\title{
A sequential model for older workers' labor transitions after a health shock*
}

\author{
Sergi Jiménez-Martín ${ }^{\dagger}$ \\ Universitat Pompeu Fabra \\ José M. Labeaga ${ }^{\ddagger}$ \\ FEDEA and UNED \\ Cristina Vilaplana Prieto ${ }^{\S}$ \\ Universidad Católica San Antonio de Murcia
}

October 19, 2005

\begin{abstract}
In this work we study older workers' (50-64) labor force transitions after a health/disability shock. We find that the probability of keeping working decreases with both age and severity of the shock. Moreover, we find strong interactions between age and severity in the 50-64 age range and none in the 30-49 age range. Regarding demographics we find that being female and married reduce the probability of keeping work. On the contrary, being main breadwinner, education and skill levels increase it. Interestingly, the effect of some demographics changes its sign when we look at transitions from inactivity to work. This is the case of being married or having a working spouse. Undoubtedly, leisure complementarities should play a role in the latter case. Since the data we use contains a very detailed information on disabilities, we are able to evaluate the marginal effect of each type of disability either in the probability of keeping working or in returning back to work. Some of these results may have strong policy implications.
\end{abstract}

KEYWORDS: HEALTH SHOCKS, DISABILITY, LABOR FORCE TRANSITIONS, OLDER WORKERS, SPAIN.

JEL: J23, J26, I12

${ }^{*}$ Financial help from Fundación BBVA and project \# BEC2002-04294-C01-C02 are gratefully acknowledged. We thank Jennifer Roberts and workshop participants at UC3M, UPF and the Dublin Health econometrics 2005 workshop.

${ }^{\dagger}$ Department of Economics, Ramon Trias Fargas 25. 08005 BARCELONA (SPAIN). sergi.jimenez@econ.upf.es

${ }^{\ddagger}$ FEDEA. Jorge Juan, 46, 28001 MADRID. jmlabeaga@fedea.es

${ }^{\S}$ Deparment of Economics, Campus Los Jerónimos, s/n. 30107 Guadalupe. Murcia. (SPAIN) CVilaplana@pdi.ucam.edu 


\section{Introduction}

Recent health related events such as the increase in life expectancy, advances in medicine and technological improvements applied to the workplace, justify to study the decisions of returning to job after a period of unemployment or inactivity (Gruber and Kubik [1], Currie and Madrian [2], Kreider and Pepper [3], Williamsom and McNamara [4]). In this work we aim at studying the labor force transitions of older workers motivated by a health shock, a sudden deterioration of their health status that generates a disability (Walker and Thompson [5], Kidd et al. [6]).

The literature on the consequences of health shocks have focussed either on their effects on retirement (Tompa [7], Bound et al. [8], Blau and Gilleskie [9]), or their effects on the relationship between unemployment and retirement (Riphahn [10], Autor and Duggan [11], Wilkins [12]), or their impact on labor earnings or wealth (Hum and Simpson [13], Hyatt [14], Ward-Batts [15], Messer and Berger [16]). Characteristics such as health status, employment prospects, labor-force attachment and income sources are investigated in order to develop a relationship between health shock and labor force transitions, including labor force exit, job change and application for benefits.

The Spanish literature on labor force transitions after a health shock is very scarce. GarcíaGómez and López-Nicolas [17] constitutes the only attempt to specifically study the consequences of a health shock on labor force status, using data from the European Community Household Panel (ECHP) during the 1994-2001 period. They find substantial labor supply effects of health shocks, proxying the health shock by a persistent deterioration of self-reported overall health status. As we shall explain latter on, we use self-reported information on a large series of potential disabilities, in contrast with the latter work. Other related studies worth to mention are Jiménez-Martín et al. [18] who study transitions out of the labor force for all EU countries present in the first three waves of the ECHP, controlling for various health variables and, Jiménez-Martín et al. [19] who study award errors in disability benefit concession. In this last study, the authors construct an "exogenous" deserving indicator in order to estimate awarding errors in disability benefit concessions.

We study labor force transitions after a health/disability shock in the 50-64 age range and conditional to the Spanish labor legislation. According to this legislation if a worker suffers a health/disability shock s/he can remain working, become temporary disabled, or, alternatively, in case $\mathrm{s} /$ he does not fulfill the necessary requirements, unemployed. Some time afterwards, at the time of the interview, and always satisfying stationary conditions, the agent can be observed in one of three states: working, unemployed or inactive. Consequently, we know the labor force status of the individual in three moments in time: before the health shock, immediately after the shock, and at the time of the interview, which corresponds with the date of the survey.

We propose a sequential logit model for the estimation of these transitions using data from the Disabilities, Deficiencies and Health Status Survey (DDHSS from now on) carried out by the Spanish Instituto Nacional de Estadística (INE) in 1999. The DDHSS is a large scale survey (+207000 interviews) aimed at studying disabilities and dependency in Spain. This data source has two main advantages: first, the information about invalidity shocks is extremely detailed; and, second, conditional on having a shock, we know the agent's labor force status at three moments in time. Using this data, the sequential model is estimated by maximum likelihood and validated against a multinomial alternative.

We draw several interesting conclusions from our analysis. First, the negative effect of the severity of the shock in the probability of keeping work increases with age in the 50-64 age range. This effect is not observed for younger workers. This can be due to the fact that the pathways to permanent disability and/or retirement increase as the individual gets older. Second, transitions back to work, after a period out of employment, are uncommon and, more important, less frequent as the individual ages. Third, there are notorious discrepancies in the marginal effect on the 
probability of keeping work by disability type. Finally, if the individual deserves a disability pension the probability of keeping work falls to zero.

The structure of the paper is the following: in section 2 we show some international evidence about labor force status of disabled people. In section 3 we describe the benefit programs available to workers $50+$. The econometric model is described in section 4 . In section 5 , we describe the sample and the characteristics of the data, and, in section 6 , we comment estimation results. In section 7 , we validate the model against a multinomial one, and evaluate its predictive accuracy. Finally, we offer some conclusions and tentative policy implications.

\section{International comparison of disabled people}

In this section we provide some evidence of the relative weight of disabled people from 50 to 64 years old, over the whole society, working people and Social Security (SS) system. We have used data from three surveys: first, the 1999 wave of the European Community Household Panel (ECHP from now on), that gathers information for all countries of the European Union with the exception of Luxembourg; second, we use the Participation and Activity Limitation Survey (PALS) for Canada during the year 2001; and, third, we use the Survey of Income and Program Participation (SIPP) corresponding to year 1997 for the United States. Despite the lack of homogeneity, we think that we can get a reasonable picture about the issue.

In Table 1 we show the distribution of the 50-64 population for EU, Canada and the US by level of disability. For EU countries, we use two questions from the ECHP: "Do you suffer any chronic health problem, illness or mental or physical disability?", and, for those answering affirmatively to the previous question "Does this health chronic problem, illness or disability prevents you from doing daily living activities?". Individuals may answer "yes, severely", "yes, moderately" or "no". The Canadian PALS classification, which is based in the WHO definition about disability, does not distinguish between moderate or severe. In the case of the US the SIPP only differentiates between severe and not severe disabilities. For a better understanding of the tables we denote with "S" severe disability, with "M" moderate and with "N" none. Around $71 \%$ of the population of the EU-14 between 50-64 years old do not suffer any disability, 19\% declares a moderate disability and only $10 \%$ a severe disability. Greece, Ireland, Italy and Spain are the countries with less disabled people.

Table 1: Distribution of the population by severity of the disability. Age 50-64

\begin{tabular}{|l|rrrrrrrrr|}
\hline & AU & B & D & FI & FR & GE & GR & IR & IT \\
\hline Severe & 6 & 9 & 9 & 12 & 12 & 14 & 8 & 4 & 5 \\
Moderate & 19 & 12 & 24 & 31 & 14 & 39 & 12 & 15 & 10 \\
None & 75 & 79 & 67 & 57 & 74 & 47 & 80 & 81 & 85 \\
\hline & $\mathrm{N}$ & $\mathrm{P}$ & $\mathrm{SP}$ & $\mathrm{SW}$ & $\mathrm{UK}$ & $\mathrm{EU}$ & $\mathrm{CA}$ & $\mathrm{USA}$ & \\
Severe & 10 & 15 & 5 & 22 & 10 & 10 & - & 18 & \\
Moderate & 21 & 20 & 17 & 17 & 18 & 19 & 22 & 11 & \\
None & 69 & 65 & 78 & 61 & 72 & 71 & 78 & 71 & \\
\hline
\end{tabular}

Source: ECHP (1999). PALS (2001). SIPP (1997). We have used the following abbreviations: AU= Austria, $\mathrm{B}=$ Belgium, $\mathrm{D}=$ Denmark, $\mathrm{FI}=$ Finland, $\mathrm{FR}=$ France, $\mathrm{GE}=$ Germany, GR= Greece, IR= Ireland, IT $=\mathrm{Italy}$, $\mathrm{N}=$ Netherlands, $\mathrm{P}=$ Portugal, $\mathrm{SP}=$ Spain, $\mathrm{SW}=$ Sweden, $\mathrm{UK}=$ United Kingdom, EU= European Union-14, $\mathrm{CA}=$ Canada, USA $=$ United States.

Table 2 presents a cross tabulation between level of disability and the highest level of education achieved. It is difficult to obtain a harmonized classification because each country has its own 
educational system. For example, for all countries, elementary education includes also non schooling, and for United States the denomination college includes also some college. This may explain some discrepancies in the figures of severe or moderate disabled people who have completed college education. Younger population has benefited from social policies for raising education rates. Only $72 \%$ of severe disabled people have completed elementary education against $61 \%$ of those without any disability. On the other hand, people with severe disabilities have less than half probability of finishing college education in relation to healthy ones. In this sense, there may be a selection effect, because if disability appears during childhood it may constitute a problem to start or remain at school, but also less educated people are more prone to suffer disabilities. For elementary education, there is a gap of nearly twenty points between moderate (94\%) and none disability (78\%) for Spain and Greece, and the proportion of severe or moderate people who have completed high school or college is, in both cases, very low.

Table 2: Distribution of the population according to maximum level of education completed and degree of disability. Age 50-64.

\begin{tabular}{|c|c|c|c|c|c|c|c|c|c|c|c|c|c|c|c|c|c|}
\hline & $\mathrm{AU}$ & $\mathrm{B}$ & $\mathrm{D}$ & FI & FR & GE & GR & IR & IT & $\mathrm{N}$ & $\mathrm{P}$ & $\mathrm{SP}$ & SW & UK & $\mathrm{EU}$ & $\mathrm{CA}$ & USA \\
\hline \multicolumn{18}{|l|}{ Severe } \\
\hline College & 1 & 12 & 11 & 10 & 7 & 13 & 4 & 5 & 0 & 5 & 2 & 3 & 11 & 22 & 7 & - & 32 \\
\hline H. School & 50 & 36 & 39 & 29 & 3 & 57 & 2 & 18 & 11 & 2 & 2 & 2 & 45 & 14 & 21 & - & 33 \\
\hline Elementary & 49 & 52 & 50 & 61 & 90 & 30 & 94 & 77 & 89 & 93 & 96 & 95 & 44 & 64 & 72 & - & 45 \\
\hline \multicolumn{18}{|l|}{ Moderate } \\
\hline College & 2 & 20 & 17 & 22 & 10 & 17 & 2 & 7 & 4 & 6 & 2 & 2 & 21 & 39 & 12 & 35 & 51 \\
\hline H. School & 61 & 31 & 46 & 28 & 5 & 54 & 4 & 20 & 14 & 3 & 3 & 4 & 41 & 14 & 25 & 17 & 20 \\
\hline Elementary & 37 & 49 & 37 & 50 & 85 & 29 & 94 & 73 & 82 & 91 & 95 & 94 & 38 & 47 & 63 & 48 & 29 \\
\hline \multicolumn{18}{|l|}{ None } \\
\hline College & 6 & 29 & 25 & 32 & 21 & 23 & 13 & 16 & 6 & 7 & 7 & 13 & 30 & 51 & 17 & 44 & 57 \\
\hline H. School & 54 & 32 & 53 & 30 & 8 & 53 & 9 & 28 & 21 & 2 & 4 & 9 & 45 & 13 & 22 & 21 & 22 \\
\hline Elementary & 40 & 39 & 22 & 38 & 71 & 24 & 78 & 56 & 73 & 91 & 89 & 78 & 25 & 36 & 61 & 35 & 21 \\
\hline
\end{tabular}

Source: ECHP (1999). PALS (2001). SIPP (1997)

Table 3 describes employment rates by disability type. Differences across employment rates may reveal the social integration degree of disabled people. Spain, Italy and Greece present the lowest figures for severe disabled working people, and Spain the lowest rate of moderate disabled working people. Even for healthy people, participation rates are in Spain lower than the average for the EU ( $22 \%$ with respect to $52 \%$ ). On the other hand, the US exhibits the greatest rates of working population for both moderate disabled and healthy people.

In Table 4 we show the proportion of people receiving either any kind of disability or illness benefits, for the set of countries already mentioned. We have not found information about disability benefits for Canada, and the US information about SS benefits was provided all together. Around $42 \%$ of severe disabled people receive a disability benefit in the EU. However, we have to consider that they may receive other private earnings, spouse income or early retirement benefits. The highest rate of coverage corresponds to Finland followed by Denmark, United Kingdom and Spain. On the other hand, Spain shows the highest fraction of moderate disabled people (31\% compared with $22 \%$ for the EU). This illustrates the fact, already mentioned by Boldrin et al. [20], that disability benefits have been used as a device to avoid unemployment for individuals approaching retirement.

Summing up the evidence for Spain: there is a lower percentage of disabled people than in other developed countries but, at the same time, disabled people present lower levels of education and 
Table 3: Employment rate by severity of the disability. Age 50-64.

\begin{tabular}{|l|rrrrrrrrr|}
\hline & AU & B & D & FI & FR & GE & GR & IR & IT \\
\hline Severe & 16 & 18 & 18 & 32 & 26 & 24 & 11 & 22 & 11 \\
Moderate & 22 & 24 & 49 & 44 & 33 & 36 & 20 & 25 & 25 \\
None & 25 & 24 & 49 & 45 & 39 & 40 & 24 & 27 & 19 \\
\hline & N & P & SP & SW & UK & EU & CA & USA & \\
Severe & 19 & 17 & 13 & 31 & 14 & 20 & - & 25 & \\
Moderate & 29 & 31 & 15 & 62 & 32 & 40 & 27 & 55 & \\
None & 29 & 40 & 22 & 65 & 44 & 40 & 56 & 71 & \\
\hline
\end{tabular}

Source: ECHP (1999). PALS (2001). SIPP (1997)

Table 4: Percentage of people receiving a disability/illness benefit by severity of the disability. Age $50-64$.

\begin{tabular}{|l|ccccccccccccccc|}
\hline & AU & B & D & FI & FR & GE & GR & IR & IT & N & P & SP & SW & UK & EU \\
\hline Severe & 34 & 63 & 71 & 73 & 31 & 23 & 26 & 50 & 49 & 47 & 35 & 69 & 51 & 69 & 42 \\
Moderate & 21 & 28 & 29 & 23 & 12 & 7 & 7 & 28 & 29 & 13 & 16 & 31 & 27 & 23 & 22 \\
None & 3 & 3 & 2 & 10 & 3 & 1 & 0 & 2 & 2 & 4 & 5 & 2 & 5 & 2 & 3 \\
\hline
\end{tabular}

Source: ECHP (1999).

participation rates, and greater probabilities of receiving a disability benefit.

\section{Public programs for old-age workers}

Table 5 summarizes the programs available after or around age 50 . Besides private pensions, there are three other public programs that may affect the behavior of old age workers: unemployment benefits, disability benefits and retirement pensions. Both the unemployment and the disability plans offer a "pathway to early retirement" alternative to the normal one (with early retirement at 60 and normal retirement at 65).

\section{Unemployment benefits and subsidies}

As many other countries, there is a contributory program to protect employees against a nonvoluntary unemployment spell. The duration of the benefits range from 120 days for 360 days of previous contribution to the system to 720 days for $2160+$ days of contribution (in both cases the days of contribution should be within the six years preceding the event). The benefit amount is 60 percent of the benefit base -the average of the contributive bases during the 180 days preceding the unemployment spell- during the first 180 days and 60 percent of the benefit base during the second 180 days. The minimum benefit amount in 1999 was 418 euros. The maximum benefit amount is a function of the number of dependent children. Without children it amounts 875 euros. With $2+$ children it amounts 1069 euros. Unemployment benefits are subject to both SS contributions and income tax.

There are two continuation programs for those who have exhausted their entitlement to contributory unemployment benefits: one for those aged 45+ (UB45+ program) and the other for those aged $52+$ (UB52+ program). The latter plan is a special subsidy for unemployed people older than 52 , who lack income sources (monthly income cannot exceed 75 of the monthly minimum wage), 
have contributed to unemployment insurance for at least 6 years in their life and, except for age, satisfy all requirements for an old-age pension. The benefit amount is 75 percent of the monthly minimum wage. This type of benefits can be drawn until the person reaches the early or normal retirement age, whatever comes first.

\section{Disability benefits}

The SS system provides insurance against both temporary and permanent illness or disability.

\section{Temporary illness or disability}

The terms of provision of the subsidy for temporary illness or disability (incapacidad laboral transitoria) has undergone frequent changes. Eligibility requires affiliation to the SS system for a minimum period that depends upon the nature of the covered risk. Common illness requires only 180 days of contributions during the last 5 years, whereas no minimum eligibility criterion is imposed for work-related accidents or illnesses.

The benefit base depends on actual earnings during the last 12 months. In case of common illness or work-unrelated accident, the subsidy is equal to 60 percent of the benefit base for each day of absence between the 4 -th and the 20 -th, and to 75 percent of the benefit base afterwards until the maximum period is reached. The maximum period for which the subsidy can be received is 18 months, after which the worker must either return to work or, conditional on passing a medical examination, be classified as "permanently disabled".

\section{Contributive disability pensions}

Contributory disability benefits (DI) are far more generous than any other old-age program, since they are not subject to penalties for young age or insufficient years of contribution. DI benefits are subject to approval by a medical examiner (notoriously, the tightness of the admissibility criteria used by examiners varies both over time and across regions) and, since the early 1990s, they have become harder to obtain at older ages. In fact, and contrary to the practice prevailing during the 1980s, it is now less common to access permanent DI benefits after age 55 . The total disability rate (as a percent of the workforce) doubled in less than ten years, from about 0.7 percent in 1975 to 1.5 percent in 1983. The 1985 reform managed to bring the phenomenon under partial control by tightening the requirements. Disability rates have since decreased, stabilizing around 0.6 percent.

Disability pensions are distinguished into contributory and non-contributory. Since our analysis is conditional on working at the beginning of the period, we limit ourselves to the contributory pensions. Eligibility and pension amounts depend on the level of disability. The 1985 reform distinguished four levels of permanent disability characterized by increasing severity. Since then, the legislation has formally reduced them to three, but it has also created a special subcase of the first level with the explicit purpose of using the disability funds to subsidize the dismissal of old workers from certain sectors or geographical areas.

The first level (incapacidad permanente total para la profesion habitual, or IPT) corresponds to inability to do the usual job. A special subcase (incapacidad permanente total cualificada para la profesión habitual, or IPTC) applies only to employees older than 55 which are in particular socioeconomic situations. The second level (incapacidad permanente absoluta, or IPA) corresponds to inability to do any kind of job. The third level (gran invalidez, or GI) requires, in addition, continued attendance by other persons in order to carry out the basic vital functions. In terms of requirements, when disability is caused by an ordinary illness, eligibility to a pension requires from 
Table 5: Public programs at older ages.

\begin{tabular}{|l|ccc|}
\hline & $\begin{array}{c}\text { Unemployment } \\
\text { insurance }\end{array}$ & $\begin{array}{c}\text { Disability } \\
\text { Insurance }\end{array}$ & $\begin{array}{c}\text { Social security } \\
\text { benefits }\end{array}$ \\
\hline 50 & cont. from $45+$ & cont. /non-cont. & n.a. \\
52 & cont. from $52+$ & cont. /non-cont. & n.a. \\
55 & cont. from $52+$ & cont. /non-cont. & n.a. \\
60 & cont. & cont. /non-cont. & ER $^{(b)}:$ cont. \\
65 & - & - & NR: cont./non-cont. \\
\hline Keys: & cont.: contributory; non-cont.: non contributory; \\
& 45+ and 52+: Special UI program for 45+ and 52+ workers enrolled in the RGSS. \\
& ER: early retirement, NR: normal retirement.
\end{tabular}

(a). There are exceptions, allowing for retirement before 60 .

5 to 15 years of contributions, depending on age. There is no contributive requirement when the disability is caused by an accident, whether or not work-related, or a professional illness.

The benefit base depends on the source of disability. In case of ordinary illness, it is computed as for old-age pensions. For work-unrelated accident, it is the average annual wage over a period of 24 consecutive months chosen by the person within the last 7 years of work. For work-related accident or professional illness, it is the average wage in the last year of work. The pension equals 55 percent of the benefit base under IPT, and increases to 75 percent under IPTC. In case of IPA, it is equal to 100 of the benefit base, whereas for GI it is equal to 100 percent of the benefit base plus another 50 percent covering the person taking care of the disabled.

\section{Retirement benefits}

The retirement program has two options: early retirement and normal retirement. Early retirement is possible from age 60 but, by year 1999, it only applied to workers who started their contributive career before 1967. The normal retirement age is 65 , although some special professions have lower normal retirement ages (miners, military personnel, policemen and fishermen are the main ones). Collective wage settlements often impose mandatory retirement at age 65 , facilitate retirement at 64 with full benefits, or encourage retirement between 60 and 63 through lump sum amounts.

\section{Econometric framework}

We consider the situation of an individual in three different moments of time for which we have information about labor force status. In period $t_{0}$, the agent is working $\left(W_{0}\right)$ and suffers a health/invalidity shock. This health shock may be a common or working disease or any type of (traffic, working, household) accident. In period $t_{1}$, immediately after the health shock, she keeps working or not. In the latter case, she can be unemployed $\left(U_{1}\right)$ or temporarily disabled $\left(I_{1}\right)$.

The main distinction between the unemployed and temporal disability status is that for the former case the contractual relation has finished and the agent has to look for a new job, whereas for the latter the worker can return to the same job if she recovers. There are several reasons for not receiving temporal disability benefits. It may be because the health shock occurred before 
affiliation to SS, because the agent is not eligible for temporal disability, or because she prefers to collect unemployment benefits.

Some time afterwards, in period $t_{2}$ (which corresponds to the time of the interview), she can be working again or not. While unemployed she can go back to work $\left(U_{1} W_{2}\right)$, remain unemployed $\left(U_{1} U_{2}\right)$ or make a transition to inactivity $\left(U_{1} I_{2}\right)$. Alternatively, while temporarily disabled, the individual can return to the previous job or move to another job $\left(I_{1} W_{2}\right)$, make a transition to unemployed $\left(I_{1} U_{2}\right)$, or remain inactive $\left(I_{1} I_{2}\right)$.

We can represent this situation using a sequential model in four steps, with six decision nodes and seven terminal nodes $\left(W_{1}, U_{1} W_{2}, U_{1} U_{2}, U_{1} I_{2}, I_{1} W_{2}, I_{1} U_{2}, I_{1} I_{2}\right)$. Decision nodes correspond to each one of the possible choices the agent faces, two in period $t_{1}$ and four in period $t_{2}$. Picture 1 shows the structure of the sequential process. Due to data restrictions, we have to assume that if the agent keeps working after the shock, at time $t_{1}$, then she is also working at $t_{2}$, that is $P\left(W_{2} \mid W_{1}\right)=1$. It seems to be an innocuous assumption for the results we obtain.
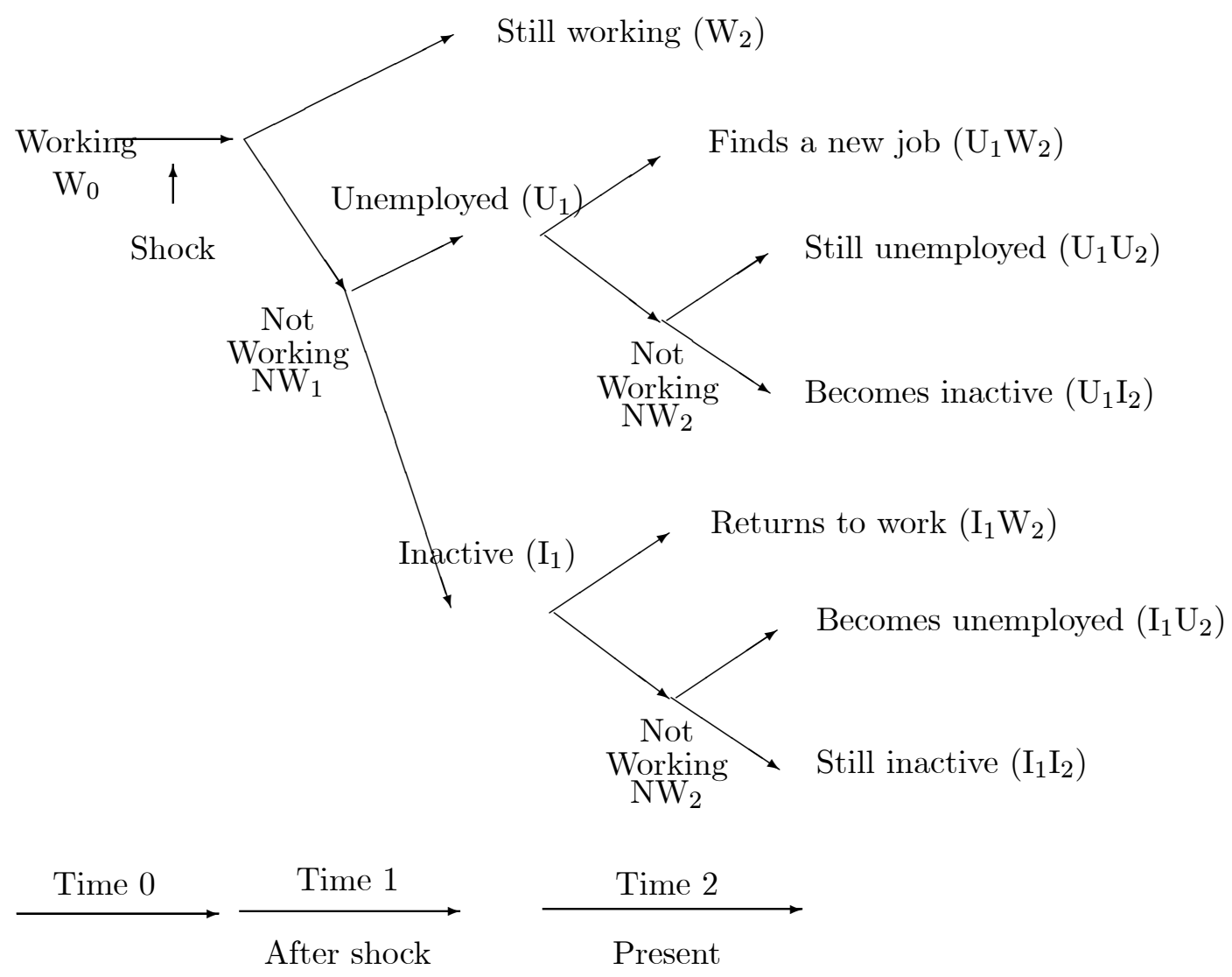

\section{Picture 1. Structure of the problem.}

For the sake of simplicity, we assume that the probability of an event in a given node is conditionally independent of choices in previous nodes. So, we consider a sequential logit model in which all decisions are conditionally independent series of binary choices (Amemiya [21]). When choosing between working or not, we will assign the value 1 to the option of working, and when choosing between unemployment and inactivity, we will assign the value 1 to the first option. We consider different set of explanatory variables $X_{1}, X_{2}, Y_{1}, Y_{2}, Z_{1}, Z_{2}$ with their corresponding coefficient vectors $\alpha, \beta, \gamma_{1}, \gamma_{2}, \delta_{1}, \delta_{2}$. These sets of explanatory variables contain common variables to all of them (sex, age, education, skill level, disabilities) and other variables specific to each decision node.

Using a logistic regression, the probability of continuing working at $t_{1}$ conditional on having a 
health shock $h_{0}$ at $t_{0}$, is given by:

$$
\operatorname{Pr}\left[W_{1}=1\right]=F\left(\alpha^{\prime} X_{1}\right)
$$

where $F(s)=\exp (s) /[1+\exp (s)]$ and, for the sake of simplicity we have skipped the conditioning variables, $h_{0}$ and $W_{0}$. The probability of being unemployed at $t_{1}$ is:

$$
\operatorname{Pr}\left[U_{1}=1\right]=\operatorname{Pr}\left[W_{1}=0\right] \operatorname{Pr}\left[U_{1}=1 \mid W_{1}=0\right]=\left[1-F\left(\alpha^{\prime} X_{1}\right)\right] F\left(\beta^{\prime} X\right)
$$

where $\operatorname{Pr}\left[U_{1}=1 \mid W_{1}=0\right]$ is the probability of becoming unemployed at $t_{1}$ conditional on not being working at $t_{1}$. Following the same procedure, we compute the probability of being unemployed at $t_{1}$ and working at $t_{2}$ :

$$
\begin{aligned}
\operatorname{Pr}\left[U_{1} W_{2}=1\right] & =\operatorname{Pr}\left[W_{1}=0\right] \operatorname{Pr}\left[U_{1}=1 \mid W_{1}=0\right] \operatorname{Pr}\left[W_{2}=1 \mid U_{1}=1, W_{1}=0\right] \\
& =\left[1-F\left(\alpha^{\prime} X_{1}\right)\right] F\left(\beta^{\prime} X_{2}\right) F\left(\gamma_{1}^{\prime} Y_{1}\right)
\end{aligned}
$$

or the probability of being unemployed at $t_{1}$ and $t_{2}$ :

$$
\begin{aligned}
\operatorname{Pr}\left[U_{1} U_{2}=1\right] & =\operatorname{Pr}\left[W_{1}=0\right] \operatorname{Pr}\left[U_{1}=1 \mid W_{1}=0\right] \\
& =\operatorname{Pr}\left[W_{2}=0 \mid U_{1}=1, W_{1}=0\right] \operatorname{Pr}\left[U_{2}=1 \mid W_{2}=0, U_{1}=1, W_{1}=0\right] \\
& =\left[1-F\left(\alpha^{\prime} X_{1}\right)\right] F\left(\beta^{\prime} X_{2}\right)\left[1-F\left(\gamma_{1}^{\prime} Y_{1}\right)\right] F\left(\delta_{1}^{\prime} Z_{1}\right)
\end{aligned}
$$

Further, the probability of being in temporary disability at $t_{1}$ and returning to work at $t_{2}$ is:

$$
\begin{aligned}
\operatorname{Pr}\left[I_{1} W_{2}=1\right] & =\operatorname{Pr}\left[W_{1}=0\right] \operatorname{Pr}\left[U_{1}=0 \mid W_{1}=0\right] \operatorname{Pr}\left[W_{2}=1 \mid U_{1}=0, W_{1}=0\right] \\
& =\left[1-F\left(\alpha^{\prime} X_{1}\right)\right]\left[1-F\left(\beta^{\prime} X_{2}\right)\right] F\left(\gamma_{2}^{\prime} Y_{2}\right)
\end{aligned}
$$

and the probability of temporary disability at $t_{1}$ and unemployed at $t_{2}$ :

$$
\begin{aligned}
\operatorname{Pr}\left[I_{1} U_{2}=1\right] & =\operatorname{Pr}\left[W_{1}=0\right] \operatorname{Pr}\left[U_{1}=0 \mid W_{1}=0\right] \\
& =\operatorname{Pr}\left[W_{2}=0 \mid U_{1}=0, W_{1}=0\right] \operatorname{Pr}\left[U_{2}=1 \mid W_{2}=0, U_{1}=0, W_{1}=0\right] \\
& =\left[1-F\left(\alpha^{\prime} X_{1}\right)\right]\left[1-F\left(\beta^{\prime} X_{2}\right)\right]\left[1-F\left(\gamma_{2}^{\prime} Y_{2}\right)\right] F\left(\delta_{2}^{\prime} Z_{2}\right)
\end{aligned}
$$

The sets of parameters $\alpha, \beta, \gamma_{1}, \gamma_{2}, \delta_{1}, \delta_{2}$ are estimated sequentially over each of the survival samples. Finally, the total probability of being working at the time of the interview $\left(t_{2}\right)$ is given by:

$$
\operatorname{Pr}\left[W_{2}\right]=\operatorname{Pr}\left[W_{1}=1\right]+\operatorname{Pr}\left[U_{1} W_{2}=1\right]+\operatorname{Pr}\left[I_{1} W_{2}=1\right]
$$

The proposed sequential model presents several advantages with respect to a multinomial one. First, we use different functions to estimate dependence across states. If workers could advance the severity of the health shock at the beginning of $t_{0}$ and how relation with economic activity is going to be affected, then a multinomial model would be more appropriate. However, workers may face uncertainties and may change their mind (depending on the number of computed working years, searching costs...). A second advantage is that is easier from a computational point of view, because the likelihood function may be maximized over the base of the different proposed stages corresponding to each of the dichotomic alternatives (Amemiya [22]). 


\section{Data}

We use data from the DDHSS carried out by the INE during the second term of 1999 [microdata website: http://www.ine.es/prodyser/micro_disca.htm]. The survey aims at identifying the actual situation of individuals with disabilities. The main method to collect the information is personal interview to all the members of the selected household. A sample of 70.402 households and 218,185 people were interviewed, from which 10,484 were less than 6 years old and 207,701 were 6 or more years. The survey consist of four different questionnaires: Household, Disabilities and Deficiencies (+6years), Limitations and Impairment (-6years) and Health questionnaire. The key parts of the survey for the purposes of this paper are the Household and Disabilities and Deficiencies (D\&D) questionnaires. The first collects socioeconomic information for all household members.

Every respondent to the Household questionnaire is asked whether s/he suffers a disability, that is, a limitation that prevents from doing daily living activities for more than one year. A survey respondent is considered to be not disabled if she does not have any difficulty in achieving any of 36 daily living activities that have been detailed. An individual may perform an infinite number of activities, but for the purpose of this survey, only most common and basic daily living activities are taken into account. The concept of disability tries to analyze if the individual is able to perform a determined activity independently of whether she really practices it or not. Those answering affirmatively have to complete the D\&D questionnaire, which includes questions about severity, forecast, origin, duration and age at the onset of the disability. It also contains questions concerning the impact of the disability on labor force status. The same person may suffer two or more disabilities that may be independent among each other (originated by different deficiencies), or they may be caused by the same problem. This survey gathers all disabilities suffered by the same respondent.

The variable severity tries to measure the degree of difficulty for performing each of the activities. It can take four values $\left(S_{i}, i=1, . ., 4\right)$ : without difficulty, moderate difficulty, severe difficulty and cannot do the activity. The variable forecast tries to capture what may be the future evolution of the disability. It can take five different values $\left(F_{j}, j=1, . .5\right)$ : recoverable, recoverable with restrictions, stable without perspectives of improvement, can go worse and it is not possible to determine.

Answers to the D\&D questionnaire are based on the individual's subjective perception about his own limitations. Several authors pointed out that there is not evidence of systematic errors in respondent answers. They sustain that self-reported measures are a trustworthy indicator of health status, and may be considered as a first approximation to true disability status (Nagi [23], Stern [24], Dwyer and Mitchell [25], Benítez-Silva et al. [26]). This result is strengthened by the confidentiality of the responses, because individuals do not have incentives to missreport in order to increase the probability of receiving any kind of SS benefit.

Finally, the Health questionnaire selects randomly one member from each household no matter she is affected or not by some disability. It contains interesting information about body mass index, habits and addictions. Unfortunately, only 12 percent of the sample have answered both the D\&D and Health questionnaires. This implies that if we select those aged between 50 and 64 who completed the D\&D and Health questionnaire, the size of the sample is much more smaller than the one we would obtain in the next section (intuitively, the sample of respondents to both will be the product of the probability of having a disability times the inverse of the household size times the total sample size). 


\subsection{Design of the various samples}

The initial sample is composed by people who answered the D\&D questionnaire. There are 19.890 observations (8.405 men and 11.485 women). Then, we have followed these steps:

1. First, we select individuals who have answered "yes" to the question "have you changed relation with economic activity as a consequence of a disability?" (sample 1: 3.620 observations). We drop those not working at the time of the health shock using the question "which was your relation with economic activity before disability?" and get a sample of 585 observations.

2. We also select people who suffered a health shock but continued working, that is, have completed the D\&D questionnaire but answered "no" to the question "have you changed relation with economic activity as a consequence of a disability" (sample 2: 1.837 observations).

3. We drop observations corresponding to individuals younger than 50 years old (1.573 observations) or older than 64 years old (1.213 observations) and obtain sample 3 (2.086 observations).

4. To determine whether people were unemployed or receiving temporal disability just after the health shock $\left(t_{1}\right)$, we use the question "which was your relation with economic activity after disability?".

5. To determine whether people returned to work or remained inactive or unemployed at the time of the survey $\left(t_{2}\right)$, we use the question "which is your present relation with economic activity?"

6. We restrict the interval between period $t_{0}$ and $t_{2}$ to a span of three years (see next section for further description). For the rest of the paper we use this final sample (sample 4) of 1.587 observations. Time $t_{2}$ corresponds to time of the interview, when respondents are asked "which is your present relation with economic activity". The structure of sample 4 is described in Picture 2 (size of sample 3 in brackets).

In order to compare the effect of a health shock on labor force status across the life cycle, we have selected a sample for respondents between 30 to 49 years old following the same steps above. There are 1,392 respondents to the D\&D questionnaire aged 30-49 years, from which 851 continued working after health shock, 66 became unemployed and 475 moved to temporal disability. If we apply the three years criterion to restrict time interval from $t_{0}$ to $t_{2}$, there is a final sample of 980 observations ( $W_{1}$ is equal to $511, U_{1}$ is 52 and $I_{1}$ is 417 ).

\subsection{Interval between the health shock and the time of the interview (present)}

It is clear that the interval between period $t_{0}$ and $t_{2}$ cannot not be left unrestricted. If it were too short the agent could not have enough time to get recovered, but if it were too long then labor force status might be influenced by other factors rather than the health shock at time $t_{0}$. To set the most appropriate length, we have considered the periods of elegibility to either unemployment or temporary disability benefits the individual is entitled while out of employment. The unemployment benefit may last a maximum of 720 days if the period of contributions is greater or equal than 2.160 days. Once unemployment benefit has finished, worker may still receive a UB +52 if he fullfils the requirements. Obviously, the receipt of any kind of subsidy will influence the incentives to find a new job. The temporary disability benefit may last a maximum of 18 months with an extension of 12 months if the medical treatment recommends so. 
For every respondent to the DDHSS we know the age at the time of the interview $\left(t_{2}\right)$, and for any respondent of the $\mathrm{D} \& \mathrm{D}$ questionnaire we know how many disabilities does she suffer and how old was she at the onset of the disability. We also know which disability was the responsible for a change in relation with economic activity. Combining this information we obtain how old the worker was at the time of the health shock $\left(t_{0}\right)$.

Since we only know the age in years of the agent, we have rounded the 30 months and consider a maximum interval of three years between health shock and time of the interview. Table 6 shows the number of available observations after imposing the restriction between $t_{0}$ and $t_{2}$. In either case, we indicate the number of working $\left(W_{1}\right)$, unemployed $\left(U_{1}\right)$ or inactive $\left(I_{1}\right)$ people after the health shock.

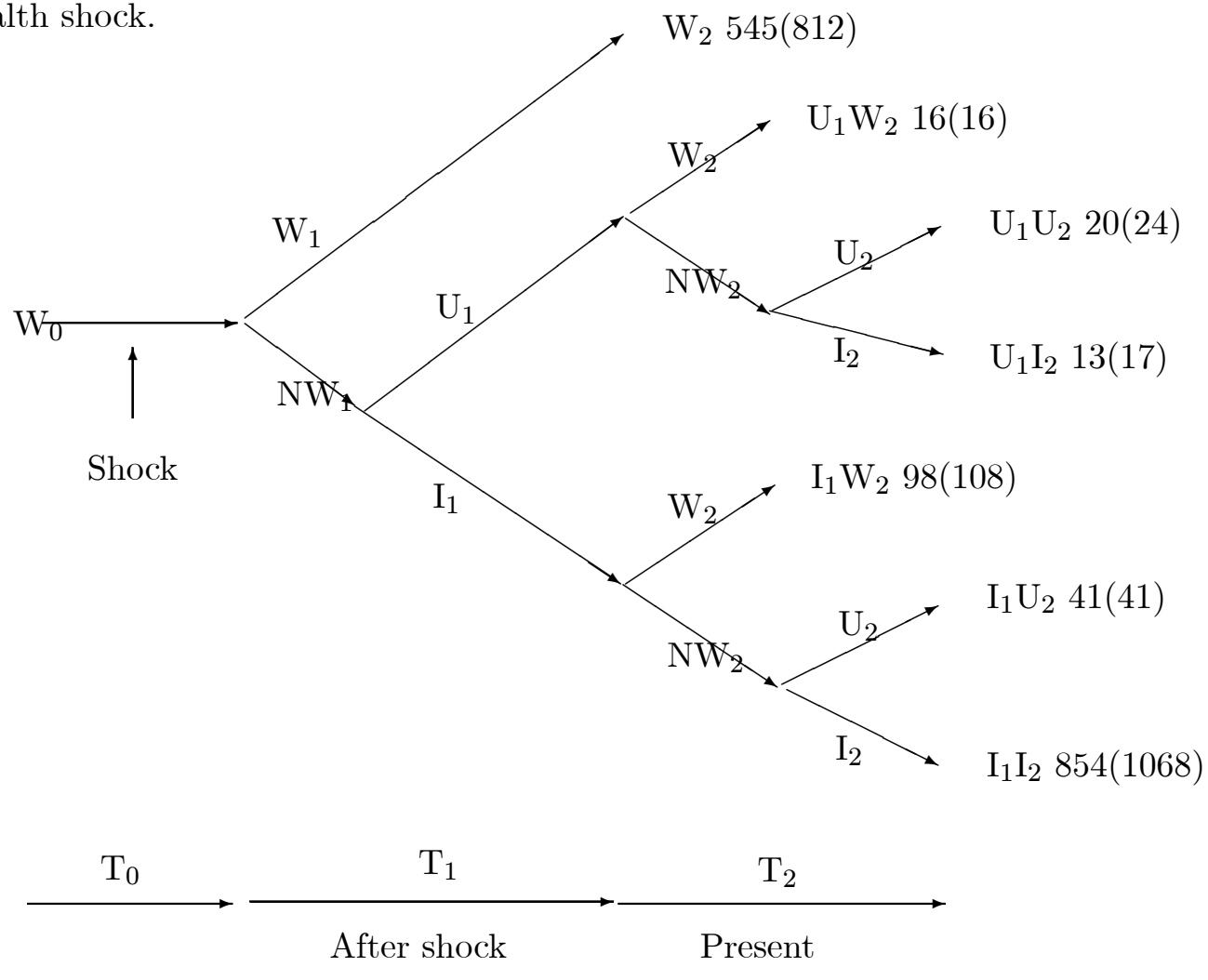

Picture 2. Structure of the sample.

For more than three fourths of the sample only three years since the health shock have passed. Moreover, if we go back in time there are no significant variations in $W_{1}$ or $U_{1}$, and only $I_{1}$ grows as the interval gets larger (the detailed figures are available upon request). Thus, the gain in the number of observations does not compensate the efficiency loss derived by mixing effects of the original health shock with other disabilities that could arise afterwards.

\subsection{Variable description and descriptive analysis}

Appendix A contains a detailed description of the survey and variables employed in the analysis. In Table B.1 of Appendix B we show descriptive statistics by transition type for the key variables employed. In Table B.2 we make evident that there are some disabilities that do not prevent from working. For example: seeing any image, global visual tasks, other visual disabilities (night vision, colors differentiation), hearing any sound, hearing strong sounds, listening the speech, communi- 
Table 6: years between the health shock and the time of the interview. Cumulative percentage of sample 3 in brackets

\begin{tabular}{|lrrrrr|}
\hline Years & 1 & 2 & 3 & 4 & 5 \\
\hline observations & $857(41.08)$ & $1297(62.12)$ & $1587(76.08)$ & $1619(77.61)$ & $1669(80.01)$ \\
$\mathrm{W}_{1}$ & $318(37.11)$ & $454(35.00)$ & $545(34.34)$ & $552(34.10)$ & $569(34.10)$ \\
$\mathrm{U}_{1}$ & $26(3.03)$ & $40(3.08)$ & $49(3.09)$ & $49(3.02)$ & $52(3.12)$ \\
$\mathrm{I}_{1}$ & $513(59.86)$ & $803(61.92)$ & $993(62.57)$ & $1018(62.88)$ & $1048(62.78)$ \\
\hline Years & 6 & 7 & 8 & 9 & 10 \\
\hline observations & $1668(80.92)$ & $1706(81.78)$ & $1713(82.12)$ & $1725(82.69)$ & $1750(83.89)$ \\
$\mathrm{W}_{1}$ & $576(34.53)$ & $581(34.06)$ & $583(34.03)$ & $587(34.03)$ & $594(33.94)$ \\
$\mathrm{U}_{1}$ & $52(3.12)$ & $53(3.11)$ & $53(3.10)$ & $54(3.13)$ & $56(3.20)$ \\
$\mathrm{I}_{1}$ & $1060(62.35)$ & $1072(62.83)$ & $1077(62.87)$ & $1084(62.84)$ & $1100(62.86)$ \\
\hline Years & 11 & 12 & 13 & 14 & 15 \\
\hline observations & $1766(84.66)$ & $1778(85.23)$ & $1791(85.86)$ & $1801(86.34)$ & $1824(87.44)$ \\
$\mathrm{W}_{1}$ & $600(33.98)$ & $605(34.03)$ & $608(33.95)$ & $613(34.04)$ & $624(34.21)$ \\
$\mathrm{U}_{1}$ & $57(3.23)$ & $57(3.21)$ & $57(3.18)$ & $57(3.16)$ & $57(3.13)$ \\
$\mathrm{I}_{1}$ & $1109(62.79)$ & $1116(62.76)$ & $1126(62.87)$ & $1131(62.80)$ & $1143(62.66)$ \\
\hline
\end{tabular}

cating through speech. This may be due to the great development of communication, information and signposting technologies.

Common disabilities among unemployed are: manipulating small objects, moving without mean of transport, moving in public transport, driving own vehicle and relating at job. Workers who have move to temporal disability usually suffer disabilities for driving own vehicle, moving not heavy objects, shopping, cooking, washing and ironing clothes. Although there are $U_{1} U_{2}$ individuals with disabilities for using utensils and tools, washing oneself, eating and drinking, cleaning the house and washing clothes, those who went to temporal disability because of the same health problems, returned to work $\left(I_{1} W_{2}\right)$ or remained inactive $\left(I_{1} I_{2}\right)$ at time $t_{2}$. This may be related to the fact that for the case of temporary disability, the worker can return to the same job, or alternatively s/he can apply for permanent disability benefits. Alternative, unemployed's options are less favorable: the probability of finding a new job is very low and retirement is conditional on meeting elegibility requirements (age above 60 and number of years contributed greater than 15, see [20] for a complete description).

In Table B. 3 we have combined the variables severity $\left(S_{i}, i=1, . ., 4\right)$, and forecast $\left(F_{j}, j=1, . .5\right)$ of the disability. In both cases higher indexes imply worse diagnosis after the health shock. We observe that severity $S_{1}$ only appears for individuals who continue working after the health shock. On the contrary, there is nobody with the highest degree of severity $\left(S_{4}\right)$ who has continued working or has returned to work after unemployment or temporal disability. The combination $S_{2} P_{3}$ groups the highest percentage of workers who have returned to job after health shock $(61.11 \%)$ and severe disability and unfavorable forecast $\left(S_{3} F_{4}\right)$ gather most of the workers that are inactive at time $t_{2}$ (47.06\% of $U_{1} I_{2}$ and $35.26 \%$ of $I_{1} I_{2}$ ). In order to account for the impact of severity, and forecast of the disability on the labor force status, in our the estimation exercise we have defined three binary variables: "severe disability", "very severe disability" and "disability benefit (DB) deserving indicator". Mean tests comparing pairwise subsamples of severe disabilities, very severe disabilities, disabilities that deserve a DB or neither one, make evident that we reject the null hypothesis of equal means for any two groups considered. 
The following table describes the construction of these variables. For the DB deserving indicator we have used the results obtained by Jiménez-Martín et al. [19]. They proposed six different criteria using information from the DDHSS to check which one was the best in replicating the legal standard of SS for deserving a permanent disability benefit. They wanted to obtain an indicator of what would have decided SS if it had had complete information from the applicant, in order to quantify how many people receives a permanent disability benefit but does not deserve it. For this purpose, they used a battery of exogeneity, consistency and rational expectation tests and concluded that the most appropriate indicator was the one described below.

Table 7: Description of severity and deserving indicators

\begin{tabular}{|l|l|l|}
\cline { 2 - 3 } \multicolumn{1}{c|}{} & \multicolumn{1}{c|}{ Severity } & \multicolumn{1}{c|}{ Forecast } \\
\hline $\begin{array}{l}\text { Severe } \\
\text { disability }\end{array}$ & $\begin{array}{l}* \text { Serious difficulty } \\
* \text { Cannot do the activity }\end{array}$ & $\begin{array}{l}* \text { Recoverable } \\
* \text { Recoverable with restrictions }\end{array}$ \\
\hline $\begin{array}{l}\text { Very severe } \\
\text { disability }\end{array}$ & $\begin{array}{l}* \text { Serious difficulty } \\
* \text { Cannot do the activity }\end{array}$ & $\begin{array}{l}* \text { Without perspectives of improvement } \\
* \text { Can go worse } \\
\text { Deserving } \\
\text { indicator }\end{array}$ \\
\hline
\end{tabular}

\section{Results}

\subsection{Probability of continuing working or becoming unemployed after the shock}

In Table B.4 we present computed predicted probabilities and marginal effects using sample 4 for a baseline case with the following characteristics: male, aged 50-54 years old, with elementary education, skilled occupation, and without any severe disability. Estimated coefficients and tstatistics of the sequential logit model are available upon request.

The probability of keeping working for the base case is very high, $82.3 \%$. Being female, or married, or having a working spouse mildly reduce it, whereas having a retired spouse or collecting DB or having to change house strongly reduce it. Alternatively, being main breadwinner, educated or white collar worker significantly increase the probability. Figure 1 shows the probability of continuing working after a health shock by age and gender. The probability decreases with age, with a peak around the age of early retirement (60 years old). The probability is higher for men than for women, which may be due to different family roles for husbands and wives, and possibly, to lower replacement rates for women. Analysis of disability characteristics shows that adverse effects on labor force status are increasing in the severity of the disability and are also worse for those who experience disability onset at older ages.

All variables related to disability reduce the probability significantly, being the effect of the deserving indicator the strongest one $(-46.1 \%)$. Apart from this, the most important disabilities that prevent continuing working are: moving outside home $(-27.5 \%)$, executing orders $(-24.1 \%)$, taking care of oneself (-18.3\%), doing housework (-16.6\%), relating (-16.4\%) and seeing (-15.6\%).

The probability of becoming unemployed conditional on not being working after a health shock is $12.46 \%$ (unconditionally $2.2 \%$ ), which implies that the probability of being inactive is $87.5 \%$ (unconditionally 15.5\%). Most of the demographics reduce the conditional probability of becoming 
unemployed and, thus, increase the probability of being inactive. In fact it only increases for unskilled workers and those without any schooling. Most likely this is so because their benefit while unemployed can be higher than their benefit while in temporary disability. Figure 2 shows the conditional probability of becoming unemployed by age and gender. We observe a decreasing trend for both gender with a peak at 52 (onset of the unemployment subsidy for workers older than 52, UB52+) and another specific for men at the age of 57 (although not as significant as the previous one). Part of the decay from age 58 onwards may be assumed due to transitions to retirement.

Regarding the effect of disability variables, most of them reduce the conditional probability of becoming unemployed. In particular the effects of the very severe $(-65.1 \%)$, deserving indicator $(-80.2 \%)$, and impairment certificate $(-64.7 \%)$ are very strong. However, we find some exceptions: having received a rehabilitation treatment increases the probability of falling into unemployment by $39.1 \%$. Further, not being able to move outside home increase this probability by $62.3 \%$, using hands and fingers by $58.78 \%$, doing housework by $31.8 \%$ and maintaining body postures by $30.4 \%$. It seems that individuals with disabilities concerning the locomotive system are more likely to turn into unemployment than those with disabilities affecting the sight, ear or nervous system (remembering, recognizing, executing orders, relating). These results are likely to be related to the type of work. White collar workers usually perform sedentary tasks with low risks of suffering work accidents, whereas skilled and unskilled workers develop a great number of displacements and are more exposed to accidents of diverse consideration (manipulation of machinery, buildings in construction, toxic substances, slightly healthy environments as the mining basins, etc.).

In what follows we are going to analyze in greater detail how these probabilities relate to severity. In this sense Table 8 shows the probability of continuing working or becoming unemployed conditional on not working at $t_{1}$ (in brackets) by severity of the disability and age group. We include the corresponding figures for prime age individuals for comparison purposes. For a given age, the more severe is the disability the lower is the probability of remaining working or moving to unemployment. The same happens for any degree of severity as the agent ages. In order to make more evident the effect of aging we present the same concepts but for prime age individuals (30-49) in panel B, where the effect of age and severity are less evident. The results are obtained from a sequential logit model for labor force transitions of individuals 30-49, and are available on request.

In order to add further evidence to the cross-effect of age and severity, we have decomposed their influence on the transition probabilities, in three parts: age effect, disability effect and interaction between age and severity (see Table 9). As expected, both effects are negative and increasing with age or severity of disability. However, the most surprising result is that the interaction is negative and significant. This may indicates that the decrease in the probability of continuing working (becoming unemployed) is greater (in absolute value) than the sum of the age and disability effects. This interaction is pushing further older workers out of the labor market. In contrast, the interaction effects for prime age workers (30-49) are almost negligible. The existence of various permanent benefit programs for older workers could explain this sharp discrepancy.

To conclude this section we study the shape of period 1 transition probabilities by age group and education and skill levels (see Table 10). Cells corresponding to combinations no schooling-white collar, no schooling-skilled and elementary schooling-skilled are empty because there is not enough sample in such situations. For a given level of education (skill) we find a positive (and increasing with age) correlation between the probability of continuing working and the skill level (education). On the contrary, as education (skill level) increases, maintaining the same level of skill (education), the probability of being unemployed decreases. Finally, for a given level of skill and education both probabilities fall with age, being the decrease greater for less educated groups. 
Table 8: Probability of continuing working or becoming unemployed ${ }^{\Im}$ (in brackets) after a health shock by severity of the disability.

Panel A: Older workers: 50-64

\begin{tabular}{|l|c|c|c|}
\hline Disability & $50-54$ & $55-59$ & $60-64$ \\
\hline Not severe & $0.7972(0.1480)$ & $0.7677(0.1268)$ & $0.6454(0.1094)$ \\
Severe & $0.6919(0.1037)$ & $0.6398(0.0734)$ & $0.3847(0.0522)$ \\
Very severe & $0.4301(0.0861)$ & $0.2132(0.0426)$ & $0.0576(0.0134)$ \\
\hline
\end{tabular}

Panel B: Prime age workers: $30-49$

\begin{tabular}{|l|c|c|c|c|}
\hline Disability & $30-34$ & $35-39$ & $40-44$ & $45-49$ \\
\hline Not severe & $0.9297(0.2414)$ & $0.9153(0.1777)$ & $0.8971(0.1563)$ & $0.8086(0.1499)$ \\
Severe & $0.8074(0.2077)$ & $0.7902(0.1417)$ & $0.7728(0.1205)$ & $0.6985(0.1139)$ \\
Very severe & $0.5790(0.1830)$ & $0.5578(0.1190)$ & $0.5439(0.0978)$ & $0.4397(0.0905)$ \\
\hline
\end{tabular}

$\Im$ : conditional to not being working in $t_{1}$.

Table 9: Marginal effect of age, severity and their interaction on the prob. of continuing working $\left(\operatorname{Pr}\left[\mathrm{W}_{1}\right]\right)$ and the prob. of becoming unemployed conditional on leaving employment $\left(\operatorname{Pr}\left[\mathrm{U}_{1} \mid N W_{1}\right]\right)$.

\begin{tabular}{|l|r|r|r|r|l|}
\hline & \multicolumn{2}{|c|}{ Sample 50-64 } & \multicolumn{2}{|c|}{ Sample 30-49 } & \\
& $\operatorname{Pr}\left[\mathrm{W}_{1}\right]$ & $\operatorname{Pr}\left[\mathrm{U}_{1} \mid N W_{1}\right]$ & $\operatorname{Pr}\left[\mathrm{W}_{1}\right]$ & $\operatorname{Pr}\left[\mathrm{U}_{1} \mid N_{1}\right]$ & \\
\hline AGE EFFECT & & & & & AGE EFFECT \\
From 50-54 to 55-59 & -3.70 & -14.32 & -1.55 & -26.38 & From 30-34 to 35-39 \\
From 50-54 to 60-64 & -19.00 & -26.08 & -3.51 & -32.25 & From 35-39 to 40-44 \\
- & - & - & -14.84 & -37.90 & From 40-44 to 45-49 \\
DISABILITY EFFECT & & & & & DISABILITY EFFECT \\
From not severe to severe & -13.21 & -29.93 & -13.15 & -14.78 & Not severe to severe \\
From not severe to very severe & -46.05 & -41.82 & -37.72 & -24.19 & Severe to very severe \\
INTERACTION EFFECT & & & & & INTERACTION EFFECT \\
Severe \& 55-59 & -2.83 & -6.16 & -0.30 & -0.14 & Severe \& 35-39 \\
Severe \& 60-64 & -19.53 & -8.72 & -0.22 & -0.05 & Severe \& 40-44 \\
Very severe \& 55-59 & - & & -0.11 & -0.14 & Severe \& 45-49 \\
Very severe \& 60-64 & -23.51 & -15.08 & -0.73 & -0.13 & Very severe \& 35-39 \\
& -27.72 & -23.05 & -0.27 & -0.05 & Very severe \& 40-44 \\
\hline
\end{tabular}


Table 10: Probability of continuing working or becoming unemployed ${ }^{\Im}$ (in brackets) after a health shock by age, skill and education levels

\begin{tabular}{|c|c|c|c|c|}
\hline \multirow[b]{2}{*}{ Skill level } & \multicolumn{4}{|c|}{ Level of Education } \\
\hline & College & High School & Elementary & No Schooling \\
\hline & \multicolumn{4}{|c|}{ Age 50-54 } \\
\hline Unskilled & $0.6075(0.1911)$ & $0.5521(0.2138)$ & $0.5357(0.2606)$ & $0.4530(0.2787)$ \\
\hline Skilled & $0.8423(0.1048)$ & $0.8097(0.1183)$ & $0.7946(0.1477)$ & \\
\hline \multirow[t]{2}{*}{ White Collar } & $0.9002(0.0745)$ & $0.8843(0.0856)$ & & \\
\hline & \multicolumn{4}{|c|}{ Age $55-60$} \\
\hline "Unskilled & 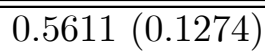 & $0.5075(0.1440)$ & $0.5130(0.1782)$ & $0.4110(0.1835)$ \\
\hline Skilled & $0.8125(0.0673)$ & $0.7761(0.0767)$ & $0.7633(0.0970)$ & \\
\hline \multirow[t]{2}{*}{ White Collar } & $0.8867(0.0476)$ & $0.8645(0.0545)$ & & \\
\hline & \multicolumn{4}{|c|}{ Age $60-65$} \\
\hline Unskilled & $0.4285(0.0792)$ & 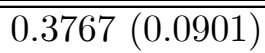 & $0.3584(0.1135)$ & 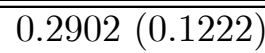 \\
\hline Skilled & $0.7157(0.0408)$ & $0.6705(0.0463)$ & $0.6532(0.0595)$ & \\
\hline White Collar & $0.8143(0.0286)$ & $0.7887(0.0329)$ & & \\
\hline
\end{tabular}

ऽ: conditional to not being working in $t_{1}$.

\subsection{Labor force transitions at $t_{2}$}

In this section we study transitions at period $t_{2}$. The main results from the analysis are presented in Table B.4. In all cases we consider the same baseline case than in the previous section. We present two types of results. First, transitions conditional on being unemployed at $t_{1}$. Second, transitions conditional on having temporal disability at $t_{1}$.

The probability of remaining unemployed for the base case is also very high (71\%). It increases for those having a working spouse, those having elementary or no schooling and for unskilled. Alternatively, it decreases significantly with age, for women, those married, and breadwinners individuals. In fact, it is very interesting to notice that the probability of remaining unemployed $\left(U_{1} U_{2}\right)$ decreases $44.09 \%$ for women. Our data indicates that they move to inactivity without receiving benefits, specially when the requirements for early retirement are not fulfilled.

The probability of finding a new job after a period of unemployment is $10.25 \%$ and it only increases for blue collar workers or for individuals whose spouse is working. It decreases in all other cases except for maintaining body postures, whose coefficient is not significant.

Concerning severity variables or the deserving indicator (or even the impairment certificate variable) the probabilities decrease substantially, which means that the probability of observing a transition to inactivity greatly increases with severity. Surprisingly, we find some disabilities that increase the probability of remaining unemployed (maintaining body postures, using hand and fingers, moving outside home).

In Figures 3 and 5 we present the conditional probabilities of remaining unemployed and moving to work by age, gender and severity of the shock, respectively. Figure 3 reveals that the probability of continuing unemployed is around $80 \%$ for men and $60 \%$ for women both with non-severe disabilities at age 50. It decreases with severity and age (mildly up to age 57 and steeper since this age) as a consequence of transition to inactivity, taking advantage of the increasing generosity with age of the Spanish benefit system.

Figure 5 shows the conditional probability of being working after a period of unemployment. 
In this case we only present results for men because of lack of data for women. The probabilities decrease significantly with age. Moreover, we detect huge differences in the probabilities by level of severity. For instance, for individuals around 50, that have suffered a moderate disability shock, the probability of finding a new job is around 20 percent (with is not much lower than for the overall population). This probability reduces to half for individuals with severe disability shocks and goes practically to zero for individuals with very severe disability shocks.

Figures 4 and 6 show the same probabilities than Figures 3 and 5 , respectively but by time out of work and age. The longer the time passed after the shock and leaving employment the lower the probability of finding a new job. Apart from this, the probability of remaining unemployed decreases quickly for those out of work for a long time period. This may be due to the joint influence of early retirement benefits and lower unemployment subsidies for older workers.

The probability of returning to work after a period of inactivity is, for the base case, small (6.1 \%). It increases for married, those having a working spouse, having a blue collar job or following a rehabilitation treatment. It decreases strongly with age for women with very severe disabilities, for individuals that deserve a DB, and, with all the disabilities. Specially interesting in this case are the strong marginal effects of the married and spouse working variables. The decrease in the probability for the case of women is very high $(-52.32 \%)$. Despite the fact that the previous job is reserved until individual recovers from the health shock, it seems that women have much more difficulties in returning to job. This may constitute evidence of discrimination against women. Non-contributive disability benefits, early retirement and houseworking are the main exits from the labor market for women. This result is corroborated by other studies ([12], [13]

The analysis of the spouse labor force status shows that the probability of the worker returning to employment is much higher if the spouse is employed. Similarly, the individual is much more likely to become inactive if the spouse is retired or is receiving a disability benefit. As in JiménezMartín et al. [18] and Riphahn [10], both findings indicate strong complementarities in leisure of both members of the couple. However, this is also compatible with the exit of the spouse from the labor market for caring the disabled individual.

Suffering a very severe disability that satisfies the deserving indicator for DB reduces the probability of finding/returning to work at $t_{2}(-80.14 \%$ and $-87.34 \%)$ and the probability of going to unemployment (-95.34\% and $-93.50 \%)$. Most workers who satisfy the deserving indicator for DB apply for contributive (or non contributive) permanent disability benefits for the case of $I_{1}, U_{1}$, respectively.

Table 11 shows the probability of returning to job by skill level, education and age group. A few clear patterns arise: first, the probability of returning to job increases with the level of skills regardless of the age group; second, the level of education hardly influences the probability of returning to work; and, third, for given skill and education levels, the probability decreases with age.

Figure 7 shows that for a given level of severity the conditional probability of returning to work after a period of inactivity is twice for men than for women at 50. From 61 onwards, the decrease is sharper for men, possibly due to the eligibility rules to early retirement. Application for early retirement benefits is conditional on contributions to SS before 1967, which is much more likely to occur for men (Boldrin et al. [20]). Figure 8 pictures the probability of returning to work by age and time out of work. At the age of 50, this probability is equal to $32 \%, 21 \%$ and $14 \%$ if the health shock happened within one year, between 1 and 2 years or between 2 and 3 years prior to the time of the interview, respectively. From 60 years on, the gap between the respective probabilities is reduced due to early retirement benefits. 
Table 11: Probability of working in $t_{2}$ after being in temporary disability in $t_{1}$

\begin{tabular}{|c|c|c|c|c|}
\hline \multirow[b]{2}{*}{ Skill level } & \multicolumn{4}{|c|}{ Level of Education } \\
\hline & College & High School & Elementary & No Schooling \\
\hline & \multicolumn{4}{|c|}{ Age 50-54 } \\
\hline Unskilled & 0.0180 & 0.0193 & 0.0207 & 0.02011 \\
\hline Skilled & 0.0458 & 0.0479 & 0.0536 & \\
\hline \multirow[t]{2}{*}{ White Collar } & 0.0845 & 0.0881 & & \\
\hline & \multicolumn{4}{|c|}{ Age 55-59 } \\
\hline Unskilled & 0.0117 & 0.0122 & 0.0137 & 0.0141 \\
\hline Skilled & 0.0301 & 0.0314 & 0.0353 & \\
\hline \multirow[t]{2}{*}{ White Collar } & 0.0560 & 0.0582 & & \\
\hline & \multicolumn{4}{|c|}{ Age 60-64 } \\
\hline Unskilled & 0.0028 & 0.0030 & 0.0032 & 0.0038 \\
\hline Skilled & 0.0075 & 0.0079 & 0.0089 & \\
\hline White Collar & 0.0144 & 0.0149 & & \\
\hline
\end{tabular}

\subsection{Impact of explanatory variables over the final probability of being working}

Suppose we want to estimate the impact of the variable $\xi_{i}$ (belonging to any of the matrices $W, X$, $Y_{1}, Y_{2}$ ) over probability of being working at the final stage. Then, we are interested in computing $\partial \operatorname{Pr}\left[W_{2} \mid \xi\right] / \partial \xi_{j}$. We can estimate it by maximum likelihood and get estimates of $F\left(\hat{\alpha}^{\prime} W\right), F\left(\hat{\beta}^{\prime} X\right)$, $F\left(\hat{\gamma}_{1}^{\prime} Y_{1}\right)$ and $F\left(\hat{\gamma}_{2}^{\prime} Y_{2}\right)$. Using $(7)$ and assuming a logistic distribution for each $F^{\prime} s$, we obtain the partial derivative with respect to $\xi_{j}$ :

$$
\begin{aligned}
\frac{\partial \operatorname{Pr}\left[\hat{O}_{2} \mid \xi\right]}{\partial \xi_{j}}= & \hat{\alpha}_{j}\left[1-F\left(\hat{\alpha}^{\prime} X_{1}\right)\right] \hat{P}_{1}++\left[-\hat{\alpha}_{j} F\left(\hat{\alpha}^{\prime} X_{1}\right)-\hat{\beta}_{j}\left[1-F\left(\hat{\beta}^{\prime} X\right)\right]\right. \\
& \left.+\hat{\gamma}_{1 i}\left[1-F\left(\hat{\gamma}_{1}^{\prime} Y_{1}\right)\right]\right] \hat{P}_{2}+\left[-\hat{\alpha}_{j} F\left(\hat{\alpha}^{\prime} X_{1}\right)-\hat{\beta}_{j} F\left(\hat{\beta}^{\prime} X\right)+\hat{\gamma}_{2 i}\left[1-F\left(\hat{\gamma}_{2}^{\prime} Y_{2}\right)\right]\right] \hat{P}_{3}
\end{aligned}
$$

where $\hat{P}_{1}=\operatorname{Pr}\left[W_{1}=1\right], \hat{P}_{2}=\operatorname{Pr}\left[U_{1} W_{2}=1\right]$ and $\hat{P}_{3}=\operatorname{Pr}\left[I_{1} W_{2}=1\right]$. We use a Taylor expansion to compute standard errors because (8) contains products of functions that are correlated among them. For example, $\hat{\alpha}_{j} F\left(\hat{\alpha}^{\prime} W\right)$ appears in the right side of (8) and may be approximated as:

$$
\begin{aligned}
\hat{\alpha}_{j} F\left(\hat{\alpha}^{\prime} X_{1}\right) & \approx \alpha_{j} F\left(\alpha^{\prime} \bar{X}_{1}\right)+\frac{\partial \alpha_{j} F\left(\alpha^{\prime} \bar{X}_{1}\right)}{\partial \alpha}\left(\hat{\alpha}_{j}-\alpha_{j}\right) \\
& =\alpha_{j} F\left(\alpha^{\prime} \bar{X}_{1}\right)+F\left(\alpha_{j}^{\prime} \bar{X}_{1}\right)\left(\hat{\alpha}_{j}-\alpha_{j}\right)+\frac{\partial \alpha_{j} F\left(\hat{\alpha}^{\prime} \bar{X}_{1}\right)}{\partial \bar{X}_{1} \alpha} \frac{\partial \bar{X}_{1} \alpha}{\partial \alpha_{j}}\left(\hat{\alpha}_{j}-\alpha_{j}\right) \\
& =\alpha_{j} F\left(\alpha^{\prime} \bar{X}_{1}\right)+\hat{\alpha}_{j} F\left(\hat{\alpha}^{\prime} \bar{X}_{1}\right)\left(1-F\left(\alpha^{\prime} \bar{X}_{1}\right)\right) \bar{X}_{1}\left(\hat{\alpha}_{j}-\alpha_{j}\right)+F\left(\alpha_{j}^{\prime} \bar{X}_{1}\right)\left(\hat{\alpha}_{j}-\alpha_{j}\right)
\end{aligned}
$$

where $\bar{X}_{1}$ is the mean of $W$, and $\alpha_{j}$ and $\hat{\alpha}_{j}$ are the true and estimated coefficients of the equation, respectively. Then:

$$
\begin{aligned}
\hat{\alpha}_{j} F\left(\hat{\alpha}^{\prime} X_{1}\right)-\alpha_{j} F\left(\alpha^{\prime} \bar{X}_{1}\right) & \approx\left[\hat{\alpha}_{j} F\left(\alpha^{\prime} \bar{X}_{1}\right)\left(1-F\left(\alpha^{\prime} \bar{X}_{1}\right)\right) \bar{X}_{1}+\left(0, \ldots, F\left(\alpha^{\prime} \bar{X}_{1}\right), \ldots, 0\right)\right]\left(\hat{\alpha}_{j}-\alpha_{j}\right) \\
& \Longrightarrow \hat{\alpha}_{j} F\left(\hat{\alpha}^{\prime} X_{1}\right)-\alpha_{j} F\left(\alpha^{\prime} \bar{X}_{1}\right) \approx C^{\prime}\left(\hat{\alpha}_{j}-\alpha_{j}\right)
\end{aligned}
$$


where $C^{\prime}$ is a row vector that gathers the expression in brackets in the right side of equation (9). If we assume that the estimated coefficients from regressions are independent among them, the asymptotic variance of $\frac{\partial \operatorname{Pr}\left[W_{2} \mid X\right]}{\partial X_{j}}$ may be obtained by a repeated use of a Taylor expansion [the exact derivation of the algebra is available on request], which gives:

$$
\operatorname{Var}\left[\frac{\partial \operatorname{Pr}\left[W_{2} \mid \xi\right]}{\partial \xi_{j}}\right] \approx d_{0}^{\prime} E(\operatorname{avar}(\hat{\alpha})) d_{0}+d_{1}^{\prime} E(\operatorname{avar}(\hat{\beta})) d_{1}+d_{2}^{\prime} E\left(\operatorname{avar}\left(\hat{\gamma}_{1}\right)\right) d_{2}+d_{3}^{\prime} E\left(\operatorname{avar}\left(\hat{\gamma}_{2}\right)\right) d_{3}
$$

where $d_{0}, d_{1}, d_{2}$ and $d_{3}$ are column vectors.

In the sequential model we have implicitly assumed that $F\left(\alpha^{\prime} X_{1}\right), F\left(\beta^{\prime} X_{2}\right), F\left(\gamma_{1}^{\prime} Y_{1}\right)$ and $F\left(\gamma_{2}^{\prime} Y_{2}\right)$ are mutually independent. The independence assumption of $\operatorname{Pr}\left[U_{1} W_{2}=1\right]$ and $\operatorname{Pr}\left[I_{1} W_{2}=\right.$ 1] with respect to $\operatorname{Pr}\left[W_{1}=1\right]$ is the main disadvantage of this model. This may be due to the presence of unobserved heterogeneity that has not been taken into account by the sequential model. Heckman and Willis [27] study the problem of heterogeneity in the context of labor supply of married women. They realize that there may be unobserved characteristics of single women that make them different from married ones, so unobserved effects cause biased estimates. We assume that controlling the initial labor force status, marital status, level of education, disabilities and other health variables is enough to control for the heterogeneity problem.

The results of our exercise as well as predicted probabilities for variation with respect to a base case are reported in Table B.5. All marginal effects are significant at standard levels. As expected, having any kind of disability contributes to a significant decrease in the probability of being working at period $t_{2}$, being the effect of the severity and deserving indicators the stronger ones. Regarding the effect of demographics, being women or having a retired spouse decrease significantly the probability of being working at $t_{2}$. Alternatively, having a working spouse, being breadwinner, younger, and the level of skill or education increase it. The increase (drop) in the probability that causes having a working spouse (spouse retired/DB) is particularly relevant. It evidences complementarities in leisure between both members of the couple. However, we must be cautious with the effect of this variable because of potential endogeneity problems.

Finally, Figure 9 further explores differences in the probabilities of being working at period $t_{2}$ by gender, skill level and age group. We appreciate that the higher the professional status, the greater the probability of being working, for all age brackets. Moreover, the probability decreases with age, regardless the professional status.

\section{Validation and forecast}

\subsection{Validation of the model}

Our aim in this section is to test the sequential structure of the model against a multinomial alternative. In estimating the sequential model, we have assumed that after suffering the health shock at time $t_{1}$, the agent may continue working $W_{1}$ or not $N W_{1}$. In this latter case, she could turn to a situation of unemployment $U_{1}$ or temporary disability $I_{1}$. Going to one of the two alternatives depends on the fulfillment of some legal requirements. Alternatively, we could have supposed that alternatives $W_{1}, U_{1}$ and $I_{1}$ are simultaneous because the worker has not enough information about the consequences of stopping work. Further, in estimating the sequential model at time $t_{2}$, we are also assuming that individual considers monetary incentives and leisure preferences when deciding whether working $W_{2}$ or not $N W_{2}$, and if she is not working, then she chooses the best alternative between unemployment $U_{2}$ and inactivity $I_{2}$. But, again, the agent may also consider $W_{2}, U_{2}, I_{2}$ simultaneously. 
In order to discriminate between both models we use three tests with the only difference among them in the initial conditions (see Picture 3 below). The first one, corresponds to period 0 where all agents are working and suffer the health shock. In the second one, we focus on individuals that turn unemployed $\left(U_{1}\right)$ and in the last one, we perform the test for those who receive temporary disability $\left(I_{1}\right)$.<smiles>[Mg][AlH2]</smiles>

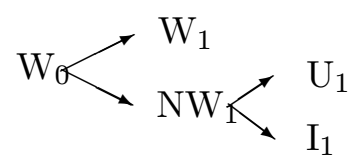<smiles>[13CH3][13CH3]</smiles><smiles>CCCN[AlH2]</smiles><smiles>[13CH3][13CH3]</smiles>

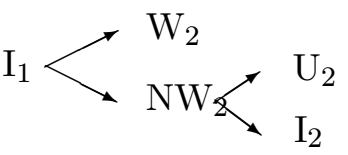

\section{Picture 3. Sequential vs simultaneous decision process}

To test these hypotheses we build a general model and we nest on it the restricted ones. Let's consider the following indirect utility model

$$
\begin{aligned}
y_{W}^{*} & =U_{W}^{\prime \prime}+w_{W} \\
y_{N W}^{*} & =U_{N W}^{\prime \prime}+w_{N W}+\lambda \max \left[U_{U \mid N W}^{\prime \prime}+w_{U \mid N W}, U_{I \mid N W}^{\prime \prime}+w_{I \mid N W}\right] \\
y_{U}^{*} & =U_{N W}^{\prime \prime}+w_{N W}+U_{U \mid N W}^{\prime \prime}+w_{U \mid N W}=U_{N W}^{\prime \prime}+w_{N W}+y_{U \mid N W}^{*} \\
y_{I}^{*} & =U_{N W}^{\prime \prime}+w_{N W}+U_{I \mid N W}^{\prime \prime}+w_{I \mid N W}=U_{N W}^{\prime \prime}+w_{N W}+y_{I \mid N W}^{*}
\end{aligned}
$$

where $y$. represents indirect utility associated to all possible alternatives and $w_{W}, w_{U \mid N W}$ and $w_{I \mid N W}$ are independent errors with a type I extreme value distribution. We suppose that $w_{N W}$ is distributed according to a generalization of a type I extreme value distribution. For further discussion about $w_{N W}$ see van Ophem and Schram [28]. The indirect utility of the non-working option $(N W)$ is a linear combination of the utility derived from the option $N W$ per se and utilities associated to states $U$ and $I$, with $\lambda \in[0,1]$. This nested model is different from the traditional one (Maddala [29], Amemiya [21]) because the underlying decision process considers the possibility of a sequential model. In fact, $\lambda$ may be interpreted as a measure of the degree of simultaneity. Depending on the value of $\lambda$ we may distinguish four cases:

1. $\lambda=0$ : we obtain a sequential model because the indirect utility from $N W$ is composed by other factors apart from utilities of $U$ and $I$, with $U_{W}^{\prime}=U_{W}^{\prime \prime}, U_{j}^{\prime}=U_{N W}^{\prime \prime}+U_{j \mid N W}^{\prime \prime}, j=U, I$ and $v_{W}=w_{W}, v_{j}=w_{N W}+w_{j \mid N W}, j=U, I$.

2. $\lambda=1$ : the model simplifies to the simultaneous one and the choice of $N W$ is determined by maximum utility between $U$ and $I$, with $U_{W}=U_{W}^{\prime \prime}, U_{j}=U_{N W}^{\prime \prime}+U_{j \mid N W}^{\prime \prime}, j=U, I$ and $\varepsilon_{W}=w_{W}, \varepsilon_{j}=w_{N W}+w_{j \mid N W}, j=U, I$.

3. $\lambda \in(0,1): y_{N W}^{*}$ is determined by characteristics of $U$ and $I$. 
4. $\lambda>1$ or $\lambda<0$ : there is no economic interpretation. However, values 0 and 1 are not in the boundary of the parameter space and so, t-statistics computed are still valid.

Probabilities associated to indirect utilities are:

$$
\begin{aligned}
P_{W} & =\frac{\exp \left(U_{W}^{\prime \prime}\right)}{\exp \left(U_{W}^{\prime \prime}\right)+\exp \left(U_{N W}^{\prime \prime}+\lambda I\right)} \\
P_{N W} & =\frac{\exp \left(U_{N W}^{\prime \prime}+\lambda I\right)}{\exp \left(U_{W}^{\prime \prime}\right)+\exp \left(U_{N W}^{\prime \prime}+\lambda V\right)} \\
P_{U} & =P_{U \mid N W} \cdot P_{N W}=\frac{\exp \left(U_{U \mid N W}^{\prime \prime}\right)}{\exp (V)} \cdot P_{N W} \\
P_{I} & =P_{I \mid N W} \cdot P_{N W}=\frac{\exp \left(U_{I \mid N W}^{\prime \prime}\right)}{\exp (V)} \cdot P_{N W}
\end{aligned}
$$

When estimating the model we assume that indirect utilities are linear and depend on a constant and a subset of observable characteristics $X_{i}$.

$$
\begin{aligned}
y_{W i}^{*} & =X_{i}^{\prime} \alpha+w_{W i} \\
y_{N W i}^{*} & =X_{i}^{\prime} \beta+\lambda V_{i}+\breve{w}_{N W i} \\
y_{U \mid N U}^{*} & =X_{i}^{\prime} \gamma+w_{U \mid N W i} \\
y_{I \mid N U}^{*} & =X_{i}^{\prime} \delta+w_{I \mid N W i}
\end{aligned}
$$

where $V_{i}=\log \left[\exp \left(X_{i}^{\prime} \gamma\right)+\exp \left(X_{i}^{\prime} \delta\right)\right]$. The error terms $w_{W i}, \breve{w}_{N W i}, w_{U \mid N W i}, w_{I \mid N W i}$ follow type I extreme value distributions. $w_{W i}$ is independent from $\breve{w}_{N W i}$, and $w_{U \mid N W i}$ and $w_{I \mid N W i}$ are independent between them. Only when $\lambda=0, \breve{w}_{N W i}$ is not correlated with $w_{U \mid N W i}$ y $w_{I \mid N W i}$. Defining $y_{j i}=1$ when individual $i$ chooses option $j=W, N W, U, I$ and zero otherwise, we have:

$$
\begin{aligned}
P_{W} & =\operatorname{Pr}\left[y_{W i}=1\right]=\frac{\exp \left(X^{\prime} \alpha\right)}{\exp \left(X^{\prime} \alpha\right)+\exp \left(X^{\prime} \beta+\lambda V\right)} \\
P_{U \mid N W} & =\operatorname{Pr}\left[y_{U i}=1 \mid y_{N W i}=1\right]=\frac{\exp \left(X^{\prime} \gamma\right)}{\exp \left(X^{\prime} \gamma\right)+\exp \left(X^{\prime} \delta\right)}
\end{aligned}
$$

note that $P_{N W}=1-P_{W}$ and $P_{I \mid N W}=1-P_{U \mid N W}$.

To identify the parameters of interest it is necessary to impose identifying restrictions. First, all $\gamma$ or $\delta$ must be equal to zero. And second, all $\beta$ must be zero. Then the log-likelihood function may be expressed as:

$$
l=\sum_{i}\left[y_{W i} \log \left(P_{W i}\right)+y_{N W i} \ln \left(P_{N W i}\right)\right]+\sum_{i} \sum_{j=U, I} y_{j i} \ln \left(P_{j \mid N W i}\right)=\log \left(L_{1}\right)+\log \left(L_{2}\right)
$$

where $L_{1}$ refers to likelihood with respect to $W$ and $N W$, and $L_{2}$ is the likelihood with respect to the choice between $U$ and $I$ given $N W$. Afterwards, the nested model is estimated by maximum likelihood. The significance of $\hat{\lambda}$ is tested by means of a Wald test (see Table 12). For the three tests $\hat{\lambda}$ is not different from zero at standard significance levels. As a results, the sequential logit model is better than the multinomial one to study the transition processes. 
Table 12: Wald test for the parameter $\lambda$

\begin{tabular}{lcc} 
& $\hat{\lambda}$ & p-value \\
\hline $\mathrm{W}_{1}, \mathrm{NO}_{1}, \mathrm{U}_{1}, \mathrm{I}_{1}$ & 0.0369 & 0.1523 \\
Given $\mathrm{U}_{1}=1: \mathrm{W}_{2}, \mathrm{NO}_{2}, \mathrm{U}_{2}, \mathrm{I}_{2}$ & 0.0568 & 0.1884 \\
Given $\mathrm{I}_{1}=1: \mathrm{W}_{2}, \mathrm{NO}_{2}, \mathrm{U}_{2}, \mathrm{I}_{2}$ & 0.0606 & 0.1945 \\
\hline
\end{tabular}

\subsection{Forecast}

In this section we test the in and out sample predictive accuracy of the sequential model against a logit model for the probability of being working at $t_{2}$. We define a binary variable that takes the value one if the individual is working at $t_{2}$ (559 observations) and zero otherwise (1.028 observations). We include the same explanatory variables than in the sequential model. The $R^{2}$ is 0.5880 and the Gamma-Kruskal statistic 0.4368 ( $\mathrm{SE}=0.021$ ). We are going to use four criteria to guarantee the robustness of the results: (a) $R^{2}$ of McKelvey and Zavonia [30]; (b) Gamma-Kruskal statistic; (c) number of predicted workers or percentage of correct forecasts (d) out of sample predictive accuracy.

First, we observe that the $R^{2}$ for any of the regressions of the sequential model is higher than for the alternative logit specification. Second, the Gamma-Kruskal statistic is nearer to 1 for any regression in Table B.4 and, in particular, for $W_{1}, U_{1} W_{2}$ and $I_{1} W_{2}$. This implies that there is a higher degree of concordance between the actual and the predicted number of people working. Third, we study the percentage of correct predictions. For this propose, we generate predicted probabilities, $\hat{p}_{i}^{M} ; M=S, L$ where $S$ or $L$ denotes either sequential or logit model. We define the following assignment rule:

$$
W_{i}=1 \quad \text { if } \quad \hat{p}_{i}^{M}>\bar{P}
$$

where $\bar{P}=559 / 1587$ is the sample mean for the total number of working people at $t_{2}$. Table 13 (PANEL A) presents the results of the analysis. The number of correct predictions is much closer to the observed number of working people at $t_{2}$ for the sequential model than it is for the logit one. This evidence holds for the whole sample as well as for each interval.

Finally, we evaluate the "out of sample" predictive capacity. For example, we eliminate those for which health shock happened more than two years ago and for the remaining observations we obtain the "out of sample" probability of being working at $t_{2}$. From a sample of 1.587 , the health shock happened less than one year ago for 857, between 1 and 2 years for 440 and between 2 and 3 years for 290. So, we keep 1297 observations when dropping the latter group. Hence, we compare the number of working individuals who suffered the shock more than 2 years ago and those predicted by the model. The results of this exercise are shown in Table 13 (PANEL B).

The sequential model predicts substantially better than its alternative. Moreover, the simpler logit model overpredicts always. Although these results are per se very significant, we perform a battery of tests for the hypothesis of equal predictive accuracy between both models ( Diebold and Mariano [31]). For the Morgan-Granger-Newbold test (Morgan [32], Granger and Newbold [33]), we have to check that the loss differential function is quadratic and the forecast errors have zero mean, are gaussian and do not present serial correlation. For the Meese and Rogoff [34] test we require the same assumptions except that of gaussianity. Note that since we have a single crosssection we cannot test for serial correlation. In Figure 10 we show density functions for standard 
Table 13: Forecasts: (sample 4)

Panel A. Forecasts: Sequential Logit and Logit for $W_{2}$.

\begin{tabular}{|l|l|l|l|c|c|}
\hline & observation & $\mathrm{W}_{2}$ & $\hat{\mathrm{p}}_{i}=1$ if & Sequential Logit & Logit for $\mathrm{W}_{2}$ \\
\hline 0-3 years & 1587 & 559 & $\hat{\mathrm{p}}_{i} \geq \frac{559}{1587}$ & 540 & 430 \\
0-1 year & 857 & 327 & $\hat{\mathrm{p}}_{i} \geq \frac{327}{857}$ & 317 & 242 \\
1-2 years & 440 & 138 & $\hat{\mathrm{p}}_{i} \geq \frac{138}{440}$ & 133 & 115 \\
2-3 years & 290 & 94 & $\hat{\mathrm{p}}_{i} \geq \frac{94}{290}$ & 90 & 80 \\
\hline
\end{tabular}

Panel B. "Out of sample" forecasts of the number of working people in $t_{2}$ (sample 4)

\begin{tabular}{|c|c|c|c|c|l|}
\hline & \multicolumn{2}{|c|}{ Sequential Logit } & \multicolumn{2}{c|}{ Logit for $\mathrm{W}_{2}$} & Sample \\
\cline { 2 - 6 } & $\%$ & Desv. & $\%$ & Desv. & $\%$ \\
\hline *0-1 years & 37.56 & -1.57 & 41.05 & 7.57 & 38.16 \\
*1-2 years & 33.80 & 4.29 & 38.67 & 19.32 & 32.41 \\
*2-3 years & 29.74 & -5.17 & 35.23 & 12.34 & 31.36 \\
\hline
\end{tabular}

PANEL C. Forecast accuracy tests (sample 4)

\begin{tabular}{lllllllll} 
& \multicolumn{2}{c}{ All sample } & \multicolumn{4}{c}{ Out-of-sample forecast } \\
forecast & \multicolumn{2}{c}{$(0-1$ year $)$} & \multicolumn{2}{c}{$(1-2$ years $)$} & \multicolumn{2}{c}{$(2-3$ years $)$} \\
test & Stat & p-value & Stat & p-value & test & p-value & Stat & p-value \\
\hline Asymptotic test & -53.21 & .0000 & -2.341 & .0010 & -2.713 & .0330 & -2.681 & .0037 \\
Sign test & -34.13 & .0000 & -2.221 & .0132 & -2.194 & .0141 & -2.704 & .0034 \\
Wilcoxon-ranked sign & -37.96 & .0000 & -2.957 & .0016 & -3.734 & .0001 & -3.332 & .0004 \\
Morgan-Granger-Newbold & -3.114 & .0009 & -17.29 & .0000 & -8.705 & .0000 & -12.77 & .0000 \\
Meese-Rogoff & 3.555 & .0002 & -9.314 & .0000 & -2.491 & .0064 & -3.901 & .0001 \\
\hline
\end{tabular}

All the test follow a $\mathrm{N}(0,1)$, except the Morgan-Granger-Newbold test that follows a t-student. 
errors corresponding to both models and the loss differential function. As it can be seen, all the assumptions are satisfied for the whole sample as well as all the "out of sample" forecasts we have performed.

In Table 13 (PANEL C) we show statistics and p-values for five different tests. For any standard significance level, all tests reject the null hypothesis of equal forecast accuracy between both models. Hence, at the light of all statistical evidence, we can conclude that the sequential logit model is substantially better than the alternative one.

\section{Concluding remarks and tentative policy implications}

In this paper we study older workers' labor force transitions after a health/disability shock using Spanish data. We propose a sequential logit model for the estimation of transitions using the DDHSS carried out by the INE in 1999. The model as well as its forecasting power are validated against a multinomial alternative.

Several interesting conclusions regarding the effect of disability variables arise from the analysis. Not surprisingly, we find that the probability of keeping work decreases with both age and the severity of the shock. More importantly, these effect are not observed for younger workers. There are notorious discrepancies in the marginal effect on the probability of keeping work by type of disability. We have evaluated the joint effect for all disability variables by means of the deserving indicator. In this sense, if the individual deserves a disability pension her probability of keeping work or returning to work after a period of inactivity falls to zero.

We also find, first, that the probability of returning to job or finding a new one after a health shock is very low and it decreases with age; and, second, there is great inertia to remain in the same situation of inactivity or unemployment. In other words, social benefits are so generous as to imply little incentives to go back to work after a shock. In fact, the percentage of people who receive a permanent disability benefit but do not deserve it increases with age, (see Jiménez-Martín et al [19]); and those who remain unemployed usually receive UB52+ benefit until the early retirement benefits are first available. In this sense, it could be convenient to achieve fiscal neutrality concerning employment, disability and unemployment benefits, in order to incentive transitions to work.

Regarding the effect of demographics our results are in line with recent literature (see, for example, Jiménez-Martín et al. [18] and Riphahn [10]). Being female or having a retired spouse or collecting DB reduces both the probability of keeping work and the probability of returning to work after inactivity. On the contrary, both probabilities increase as the level of education or skill increase. The effects of other demographics such as married and spouse working are contradictory because they decrease the probability of keeping work but increase the probability of returning to work after a period of inactivity. However, our evaluation of the whole probability of being working at period $t_{2}$ evidences that their total effect is positive.

Note that the strong total effect of spouse working implies substantial complementarities in leisure of both members of the couple. Apart from this, being female reduces significantly the probability of observing a transition, specially in the case of transitions back to work. This may constitute evidence of gender discrimination.

Jointly, all the above facts may indicate that social employment promotion measures for (recoverable) temporary disability workers are not as effective as they should be, because the relative generosity of disability or retirement benefits eases transitions to inactivity, even for those suffering moderate disability shocks. Our data reveal that only $1.21 \%$ of the agents who have returned to work have benefited from some of these measures.

According to data from the Ministry of Labor and Social Issues, most efforts are concentrated 
in sheltered centers in which more than $70 \%$ of the workers suffer permanent disabilities. However, there are other alternatives such as apprenticeship contracts, subsidies for becoming self-employer, and for those unemployed receiving the UB52+ subsidy there exist a specific contract in which the employer and the Social Security share the payment of the subsidy at $50 \%$ in case of indefinite contracts, and the company receives fiscal benefits.

Despite these orientations, the concept of rehabilitation of people who become ill or disabled is often organized in medico-pedagogical institutions and the process is reduced to a functional limitation programme. Social and professional aspects take a minor role. For example, work and housing adaptation are seldom taken into account, and architectural and other forms of barriers are eliminated with difficulties. 


\section{References}

[1] Gruber, J., Kubik, J., 1997. Disability insurance rejection rates and the labor supply of older workers. Journal of Public Economics 64, 1-23.

[2] Currie, J., Madrian, B. C., 1999. Health, health insurance and the labor market. In Ashenfelter, O. and Card, D., Handbook of Labor Economics. Elsevier, Amsterdam, pp. 3309-3416.

[3] Kreider, B., Pepper, J., 2002. Disability and employment: re-evaluating the evidence in light of reporting errors. CRR WP 6.

[4] Williamsom, J., McNamara, T., 2002. The effects of unplanned changes in marital and disability status: interrupted trajectories and labor force participation. CRR WP 6.

[5] Walker, I., Thompson, A., 1996. Disability, wages and labor force participation: evidence from UK panel data. WP Series Department of Economics, Keele University, 96/14.

[6] Kidd, M., Sloane, P., Ferko, I., 2002. Disability and labour market: and analysis of British males. Journal of Health Economics 19, 961-981.

[7] Tompa, E., 1999. Transitions to retirement: determinants of age Social Security take up. Social and Economic Dimensions of an Aging Population Resarch, Working Paper number 6.

[8] Bound, J., Schoenbaum, M., Stinebrickner, T., Waidman, T., 1999. The dinamics effects of health on labor force transitions of older workers. Labor Economics 6, 179-202.

[9] Blau, D. M.., Gilleskie, D. B., 2001. The effect of health on employment transitions of older men. Research in Labor Economics 20, 35-65.

[10] Riphahn, R. T., 1999. Income and employment effects of health shocks. A test case for the German welfare state. Journal of Population Economics 12, 363-389.

[11] Autor, D. H., Duggan, M. G., 2001. The rise in disability recipiency and the decline in unemployment. NBER Working Paper 8336.

[12] Wilkins, R. K., 2004. The effects of disability on labor force status in Australia. The Australian Economic Review 37, 359-382.

[13] Hum, D., Simpson, W., 1996. Canadians with disability and the labour market. Canadian Public Policy 22, 287-299.

[14] Hyatt, D. E., 1996. Work desincentives of workers' compensation permanent partial disability benefits: evidence for Canada. Canadian Journal of Economics 29, 289-308.

[15] Ward-Batts, J., 2001. Health, wealth and gender: do health shocks of husbands and wives have different impacts on household wealth? University of Michigan. Michigan Retirement Research Center WP016.

[16] Messer, J. P., Berger, M. C., 2004. The impact of health on employment, wages and hours worked over the life cycle. The Quaterly Review of Economics and Finance 44, 102-121.

[17] Garcia-Gómez, P., López-Nicolas, A., 2005. Health shocks, employment and income in the Spanish labour market. Manuscript. 
[18] Jiménez-Martín, S., Labeaga, J. M, Martínez, M., 1999. Health Status and Retirement decisions of older European couples," WP 99-82(30) Universidad Carlos III de Madrid.

[19] Jiménez-Martín, S., Labeaga, J. M., Vilaplana, C., (2005), Type I classification error and permanent disability benefits in Spain. Mimeo.

[20] Boldrin, M., Jiménez-Martín S. and Peracchi, F.,1999. Social Security and Retirement in Spain. In J. Gruber and D. Wise, Social Security and Retirement around the World, Chicago University Press for the NBER.

[21] Amemiya, T., 1975. Qualitative response models. Annals of Economic and Social Measurement $4,362-373$.

[22] Amemiya, T., 1985. Advanced Econometrics. Cambridge; Harvard University Press.

[23] Nagi, S., 1979. The concept and measurement of disability. In Disability Policies and Goverment Policies. New York: Praeger.

[24] Stern, S., 1989. Measuring the effect of disability on the labor force participation. Journal of Human Resources 24, 361-395.

[25] Dwyer, D., Mitchell, O., 1998. Health problems as determinants of retirement: are self-rated measures endogenous? National Bureau of Economic Research. Working Paper 6503.

[26] Benítez-Silva, H., Hiu-Man, C., Rust, J., Shedvasser, S., 1999. An empirical analysis of the Social Security Disability, application, appeal, and award process. Labour Economics 6, 147178.

[27] Heckman, J. J., Willis, R. T., 1977. A Beta-logistic model for the analysis of sequential labor force participation by married women. Journal of Political Economy 85, 27-58.

[28] van Ophem, H., Schram, A., 1997. Sequential and multinomial logit: a nested model. Empirical Economics 22, 131-152.

[29] Maddala, G. S., 1983. Limited-dependent and qualitative variables in econometrics. Cambridge University Press, Cambridge.

[30] McKelvey, R., Zavoina, W., 1975. A statistical model for the analysis of ordinal level dependent variables. Journal of Mathematical Sociology 4, 103-120.

[31] Diebold, F. X., Mariano, R. S., 1995. Comparing predictive accuracy. Journal of Business and Economic Statistics 13, 251-269.

[32] Morgan, W. A., 1939-1940. A test for significance of the difference between the two variances in a sample from a normal bivariate population. Biometrika 31, 13-19.

[33] Granger, C. W. J., Newbold, P., 1977. Forecasting economic time series. Orlando, FL: Academic Press.

[34] Meese, R. A., Rogoff, K., 1988. What is real? The exchange rate interest differential relation over the modern floating rate period. Journal of Finance 43, 933-948. 


\section{A Description of the variables}

\section{Disabilities}

For the descriptive analysis we have defined a binary indicator for each one of the 36 disabilities detailed in the Disabilities and Deficiencies Questionnaire, that is, a variable that takes the value one if the respondent declares to suffer this disability and the value zero in other case. For the estimation of the sequential logit model, we have grouped the 36 disabilities in the following 10 groups and have defined a binary variable for each one.

1. Seeing: Receiving any image, Global visual tasks, Detailed visual tasks, Other visual disabilities

2. Hearing: Hearing any sound, Hearing strong sounds, Listening the speech

3. Communicating: Communicating through speech, Communicating through alternative language, Communicating through not sealed gestures, Communicating through conventional writing - reading

4. Learning, applying knowledge and developing topics: Recognizing persons/objects and being orientated in space and in time, Remembering information and recent or past episodes, Dealing and executing simple orders and/or doing simple tasks, Dealing and executing complex orders and/or doing complex tasks

5. Moving: Changes and maintenance of body positions, Getting up and down and standing up, Moving inside home

6. Using arms and hands: Moving/transporting not very heavy objects, Using utensils and tools, Manipulating small objects with hands and fingers

7. Moving out of home: Moving without way of transport, Moving in public transport, Driving own vehicle

8. Looking after oneself: Washing oneself, Controlling physical needs, Dressing and undressing, Eating and drinking

9. Doing housework: Do the shopping, Cooking, Washing and ironing clothes, Cleaning the house, Looking after the well-being of the family

10. Relating to people: Supporting relations of fondness with close relatives, Doing friends, Relating to companions, chiefs and subordinates 


\section{Socioeconomic variables}

Married

Spouse working

Spouse retired/DB

Breadwinner

Caretaker

Technical aid

Impairment certificate

Rehabilitation treatment

Change of house

No schooling

Elementary

High School

College

Unskilled

Skilled

White collar
1 if he/she is married

1 if spouse is working

1 if spouse is retired or receiving disability benefit

1 if he/she is the household main sustainer

\section{Health variables}

1 if he/she needs somebody to take care of him/her

1 if he/she needs any kind of device to do the activity

1 if he/she has received an impairment certificate

1 if he/she has finished a rehabilitation treatment

1 if he/she has moved because of a disability

\section{Education}

(omitted category)

1 if he/she has only finished elementary education

1 if he/she has only finished high school or vocational training

1 if he/she is a graduate or bachelor

\section{Skill level of the job previous to the shock}

(omitted category)

1 if he/she is a qualified worker in agriculture, cattle raising, fishing, industry, mining industry, construction, services

1 if management, public administration, white collars,

white collar workers and intellectuals

\section{B Tables}

Table B.1. Mean values of variables (\%) (sample 4)

\begin{tabular}{|l|r|r|r|r|r|r|r|r|r|r|}
\hline & $\mathrm{W}_{1}$ & $\mathrm{U}_{1}$ & $\mathrm{I}_{1}$ & $\mathrm{U}_{1} W_{2}$ & $\mathrm{U}_{1} \mathrm{U}_{2}$ & $\mathrm{U}_{1} \mathrm{I}_{2}$ & $\mathrm{I}_{1} W_{2}$ & $\mathrm{I}_{1}$ & $\mathrm{U}_{2}$ & $\mathrm{I}_{1} \mathrm{I}_{2}$ \\
\hline Man & 70.32 & 61.40 & 67.30 & 100 & 61.11 & 52.94 & 88.89 & 37.5 & 67.17 \\
Spouse working & 81.55 & 71.93 & 78.31 & 100 & 69.44 & 70.59 & 83.33 & 50 & 78.42 \\
Spouse retired/DB & 45.21 & 32.12 & 39.23 & 70 & 55.37 & 18.11 & 65.39 & 43.51 & 23.25 \\
Main breadwinner & 2.68 & 27.45 & 33.38 & 14 & 10.38 & 60.45 & 17.27 & 11.84 & 54.10 \\
Impairment certificate & 76.67 & 59.65 & 69.10 & 75 & 61.11 & 52.94 & 88.89 & 25 & 69.10 \\
Change of house & 18.26 & 19.30 & 40.02 & 25 & 16.67 & 23.53 & 61.11 & 25 & 39.80 \\
Rehabilitation treatment & 1.85 & 8.77 & 6.24 & 25 & 5.56 & 11.76 & 5.56 & 12.5 & 6.88 \\
Elementary & 47.66 & 35.09 & 29.42 & 0 & 38.89 & 35.29 & 33.33 & 50 & 29.22 \\
High School & 16.75 & 17.54 & 46.95 & 50 & 44.44 & 52.94 & 50 & 25 & 40.81 \\
College & 8.87 & 3.51 & 5.18 & 0 & 19.44 & 17.65 & 16.67 & 25 & 10.75 \\
White collar & 25.37 & 3.51 & 10.44 & 25 & 5.56 & 0 & 11.11 & 12.5 & 5.04 \\
Skilled & 62.44 & 52.63 & 46.84 & 50 & 47.22 & 67.41 & 66.67 & 62.5 & 46.43 \\
[50,55] & 33.50 & 40.35 & 21.28 & 50 & 44.44 & 29.41 & 55.56 & 50 & 20.57 \\
(55,60] & 36.21 & 33.33 & 30.48 & 25 & 36.11 & 29.41 & 22.22 & 37.5 & 30.56 \\
60,65] & 30.29 & 26.32 & 48.23 & 25 & 19.44 & 41.18 & 22.22 & 12.5 & 48.87 \\
Technical aid & 22.29 & 24.56 & 27.03 & 25 & 25 & 23.53 & 22.22 & 25 & 27.12 \\
Caretaker & 17.86 & 24.56 & 46.01 & 25 & 19.44 & 35.29 & 22.22 & 25 & 46.52 \\
Severe disability & 1.97 & 10.53 & 24.19 & 25 & 11.11 & 11.76 & 11.11 & 12.50 & 24.03 \\
Very severe disability & 44.83 & 57.89 & 66.72 & 50 & 55.56 & 64.71 & 33.33 & 75 & 67.17 \\
Deserving indicator & 51.32 & 55.87 & 85.53 & 56.68 & 64.59 & 64.59 & 50.17 & 82.98 & 92.59 \\
\hline
\end{tabular}


Table B.2. Description of very severe disabilities (\%) (sample 4).

\begin{tabular}{|c|c|c|c|c|c|c|c|c|c|}
\hline & $W_{1}$ & $U_{1}$ & $I_{1}$ & $U_{1} W_{2}$ & $U_{1} U_{2}$ & $U_{1} I_{2}$ & $I_{1} W_{2}$ & $\mathrm{I}_{1} \mathrm{U}_{2}$ & $I_{1} I_{2}$ \\
\hline Seeing any image & 2.75 & 0 & 1.35 & 0 & 0 & 0 & 0 & 0 & 1.38 \\
\hline Global visual tasks & 13.19 & 12.12 & 10.34 & 0 & 10 & 18.18 & 0 & 16.67 & 10.38 \\
\hline Detailed visual tasks & 14.01 & 15.15 & 11.33 & 50 & 10 & 18.18 & 0 & 33.33 & 11.25 \\
\hline Other visual disabilities & 6.32 & 3.03 & 4.31 & 0 & 5 & 0 & 0 & 0 & 4.38 \\
\hline Hearing any sound & 8.52 & 6.06 & 0.86 & 0 & 10 & 0 & 0 & 0 & 0.88 \\
\hline Hearing strong sounds & 3.85 & 0 & 1.23 & 0 & 0 & 0 & 0 & 0 & 1.25 \\
\hline Listening the speech & 14.29 & 9.09 & 5.30 & 0 & 10 & 9.09 & 0 & 0 & 5.38 \\
\hline Communicating through speech & 6.32 & 3.03 & 3.82 & 0 & 5 & 0 & 0 & 0 & 3.88 \\
\hline Comm. alternative languages & 0.55 & 0 & 0.86 & 0 & 0 & 0 & 0 & 0 & 0.88 \\
\hline Comm. not sealed gestures & 0.55 & 0 & 0.99 & 0 & 0 & 0 & 0 & 0 & 1 \\
\hline Comm. reading-writing & 2.47 & 3.03 & 7.14 & 0 & 0 & 9.09 & 0 & 0 & 7.25 \\
\hline Recognizing people & 0.27 & 3.03 & 2.22 & 0 & 0 & 9.09 & 0 & 0 & 2.25 \\
\hline Remembering information & 1.10 & 3.03 & 4.31 & 0 & 0 & 9.09 & 0 & 0 & 4.38 \\
\hline Executing simple orders & 0.27 & 0 & 2.22 & 0 & 0 & 0 & 0 & 0 & 2.25 \\
\hline Executing complex orders & 0.82 & 3.03 & 4.80 & 0 & 0 & 9.09 & 0 & 0 & 4.88 \\
\hline Maintaining body postures & 10.16 & 6.06 & 17.49 & 0 & 0 & 18.18 & 33.33 & 33.33 & 17.25 \\
\hline Getting up and down & 16.76 & 24.24 & 25.62 & 50 & 20 & 27.27 & 33.33 & 33.33 & 25.5 \\
\hline Moving inside home & 7.42 & 12.12 & 14.90 & 0 & 15 & 9.09 & 0 & 0 & 15.13 \\
\hline Moving not heavy objects & 19.51 & 18.18 & 34.24 & 0 & 10 & 36.36 & 0 & 0 & 34.38 \\
\hline Using utensils and tools & 14.56 & 18.18 & 25.37 & 0 & 15 & 27.27 & 0 & 0 & 25.5 \\
\hline Manipulating small objects & 13.19 & 15.15 & 16.87 & 0 & 15 & 18.18 & 0 & 0 & 16.88 \\
\hline Moving without transport & 16.21 & 24.24 & 32.76 & 0 & 20 & 36.36 & 0 & 16.67 & 33.13 \\
\hline Moving using public transport & 15.38 & 27.27 & 31.28 & 50 & 20 & 36.36 & 0 & 0 & 31.63 \\
\hline Driving own vehicle & 35.99 & 39.39 & 49.63 & 50 & 35 & 45.45 & 0 & 0 & 50 \\
\hline Washing oneself & 3.02 & 12.12 & 12.93 & 50 & 5 & 18.18 & 16.67 & 0 & 13 \\
\hline Controlling physical needs & 1.37 & 0 & 4.68 & 0 & 0 & 0 & 0 & 0 & 4.75 \\
\hline Dressing and undressing & 4.40 & 9.09 & 12.56 & 0 & 5 & 18.18 & 16.67 & 0 & 12.63 \\
\hline Eating and drinking & 0.27 & 3.03 & 3.08 & 0 & 5 & 0 & 0 & 0 & 3.13 \\
\hline Do the shopping & 11.26 & 15.15 & 31.65 & 50 & 5 & 27.27 & 16.67 & 16.67 & 31.88 \\
\hline Cooking & 5.22 & 6.06 & 20.07 & 0 & 0 & 18.18 & 0 & 0 & 20.38 \\
\hline Washing and ironing clothes & 8.24 & 6.06 & 27.22 & 0 & 10 & 18.18 & 0 & 0 & 27.50 \\
\hline Cleaning the house & 12.36 & 18.18 & 34.61 & 0 & 10 & 36.36 & 0 & 0 & 34.88 \\
\hline Looking after the family & 5.22 & 3.03 & 20.81 & 0 & 0 & 9.09 & 0 & 0 & 21.13 \\
\hline Relations with family & 0.55 & 3.03 & 2.83 & 0 & 5 & 0 & 0 & 0 & 2.88 \\
\hline Making friends & 3.30 & 6.06 & 8.74 & 0 & 5 & 9.09 & 0 & 16.67 & 8.75 \\
\hline Relating at work & 6.59 & 12.12 & 11.95 & 50 & 10 & 9.09 & 16.67 & 16.67 & 11.88 \\
\hline
\end{tabular}

Table B.3. Fraction of sample by combinations of severity and forecast by transition.

\begin{tabular}{|c|c|c|c|c|c|c|c|c|c|}
\hline & $W_{1}$ & $\mathrm{U}_{1}$ & $\mathrm{~T}_{2}$ & $\mathrm{U}_{1} \mathrm{~W}_{1}$ & $\mathrm{U}_{1} \mathrm{U}_{2}$ & $\mathrm{U}_{1} \mathrm{I}_{2}$ & $\mathrm{I}_{1} \mathrm{~W}_{2}$ & $\mathrm{I}_{1} \mathrm{U}_{2}$ & $\mathrm{I}_{1} \mathrm{I}_{2}$ \\
\hline$S_{1} F_{1}$ & 0.12 & 0 & 0 & $\begin{array}{ll}1 \\
& 0\end{array}$ & $\begin{array}{ll}1 \\
\end{array}$ & 0 & $\begin{array}{ll} \\
0\end{array}$ & $\begin{array}{ll}1 \\
\end{array}$ & 0 \\
\hline$S_{1} F_{2}$ & 0.12 & 0 & 0 & 0 & 0 & 0 & 0 & 0 & 0 \\
\hline$S_{1} F_{3}$ & 2.96 & 0 & 0 & 0 & 0 & 0 & 0 & 0 & 0 \\
\hline$S_{1} F_{4}$ & 0.12 & 0 & 0 & 0 & 0 & 0 & 0 & 0 & 0 \\
\hline$S_{1} F_{5}$ & 0 & 0 & 0 & 0 & 0 & 0 & 0 & 0 & 0 \\
\hline$S_{2} F_{1}$ & 3.20 & 0 & 1.23 & 0 & 0 & 0 & 0 & 0 & 1.26 \\
\hline$S_{2} F_{2}$ & 5.42 & 3.51 & 2.88 & 0 & 5.56 & 0 & 5.56 & 0 & 2.85 \\
\hline$S_{2} F_{3}$ & 29.19 & 29.82 & 25.97 & 25 & 30.56 & 29.41 & 61.11 & 12.5 & 25.52 \\
\hline$S_{2} F_{4}$ & 29.43 & 17.54 & 33.03 & 25 & 16.67 & 17.65 & 11.11 & 25 & 33.42 \\
\hline$S_{2} F_{5}$ & 4.31 & 5.26 & 3.86 & 25 & 5.56 & 0 & 0.00 & 0 & 3.95 \\
\hline$S_{3} F_{1}$ & 0.37 & 0 & 0.99 & 0 & 0 & 0 & 0.00 & 0 & 1.01 \\
\hline$S_{3} F_{2}$ & 0.99 & 8.77 & 2.71 & 0 & 8.33 & 11.76 & 5.56 & 12.5 & 2.60 \\
\hline$S_{3} F_{3}$ & 14.29 & 15.79 & 17.83 & 25 & 13.89 & 17.65 & 22.22 & 12.5 & 17.80 \\
\hline$S_{3} F_{4}$ & 18.23 & 29.82 & 35.09 & 0 & 25 & 47.06 & 5.56 & 75 & 35.26 \\
\hline$S_{3} F_{5}$ & 2.71 & 3.51 & 3.04 & 0 & 2.78 & 5.88 & 0 & 0 & 3.11 \\
\hline$S_{4} F_{1}$ & 0 & 0 & 0.41 & 0 & 0 & 0 & 0 & 0 & 0.42 \\
\hline$S_{4} F_{2}$ & 0 & 1.75 & 1.48 & 0 & 2.78 & 0 & 0 & 0 & 1.43 \\
\hline$S_{4} F_{3}$ & 0 & 12.28 & 19.39 & 0 & 13.89 & 11.76 & 0 & 12.5 & 19.40 \\
\hline$S_{4} F_{4}$ & 0 & 10.53 & 15.26 & 0 & 8.33 & 17.65 & 0 & 12.5 & 15.53 \\
\hline$S_{4} F_{5}$ & 0 & 3.51 & 3.29 & 0 & 0 & 50 & 0 & 0 & 3.33 \\
\hline
\end{tabular}

The variable severity takes one of four values $\left(S_{i}, i=1, . ., 4\right)$ : without difficulty, moderate difficulty, severe difficulty and can not do the activity. The variable forecast can take five different values $\left(F_{j}, j=1, . .5\right)$ : recoverable, recoverable with restrictions, stable without perspectives of improvement, can go worse, and it is not possible to determine. 
Table B.4. Marginal effects for the sequential logit model (sample 4)

\begin{tabular}{|c|c|c|c|c|c|c|}
\hline & $W_{1} W_{2}$ & $U_{1}$ & $U_{1} W_{2}$ & $U_{1} U_{2}$ & $T_{1} W_{2}$ & $T_{1} U_{2}$ \\
\hline Baseline & 0.8234 & 0.12459 & 0.1025 & 0.7099 & 0.0614 & 0.2512 \\
\hline Women & $-2.32^{* *}$ & $-3.48^{* *}$ & & $-44.09^{* *}$ & $-52.75^{* *}$ & $-3.63^{* *}$ \\
\hline Married & $-3.67^{* *}$ & $-17.94^{* *}$ & & $-29.92^{* *}$ & $48.43^{* *}$ & $-28.40^{* *}$ \\
\hline Spouse working & $-2.65^{* *}$ & $1.27^{* *}$ & $30.52^{* *}$ & $12.26^{* *}$ & $47.70^{* *}$ & $11.41^{* *}$ \\
\hline Spouse retired/DB & $-12.72^{* *}$ & $-1.08^{* *}$ & $-44.80^{* *}$ & $-31.81^{* *}$ & $-58.77^{* *}$ & $-33.6^{* * *}$ \\
\hline Main breadwinner & $10.33^{* *}$ & $-41.09^{* *}$ & & $-17.50^{* *}$ & $119.73^{* *}$ & $-87.22^{* *}$ \\
\hline Impairment certificate & $-13.55^{* *}$ & $-64.67^{* *}$ & $-76.01^{* *}$ & $-14.15^{* *}$ & $-44.10^{* *}$ & $-47.89^{* *}$ \\
\hline Change of house & $-17.49^{* *}$ & $-44.22^{* *}$ & $-74.23^{* *}$ & $-37.30^{* *}$ & $-48.47^{* *}$ & $-41.29^{* *}$ \\
\hline Rehabilitation treatment & $-6.67^{* *}$ & $39.19^{* *}$ & & $20.95^{* *}$ & $8.62^{* *}$ & $95.78^{* *}$ \\
\hline Age $(55,60]$ & $-3.75^{* *}$ & $-35.31^{* *}$ & $-33.04^{* *}$ & $-8.95^{*}$ & $-33.72^{* *}$ & $-8.89^{* *}$ \\
\hline Age $\left(60,65^{\circ}\right.$ & $-16.67^{* *}$ & $-61.28^{* *}$ & $-65.45^{* *}$ & $-48.33^{* *}$ & $-40.68^{* *}$ & $-56.58^{* *}$ \\
\hline No Elementary & -17.89 & 30.40 & -15.65 & 31.98 & 14.85 & 3.41 \\
\hline Elementary & $-2.41^{* *}$ & $24.70^{* *}$ & $-3.38^{* *}$ & $16.84^{* *}$ & $12.12^{* *}$ & $25.64^{* *}$ \\
\hline College & $4.41^{* *}$ & $-11.66^{* *}$ & & & $-4.42^{* *}$ & $-9.94^{* *}$ \\
\hline Unskilled & -31.65 & 17.57 & -21.10 & 21.67 & -61.77 & 2.53 \\
\hline White collar & $9.99^{* *}$ & $-28.12^{* *}$ & $12.43^{*}$ & & $83.51^{* *}$ & $-7.57^{*}$ \\
\hline Severe disability & $-4.55^{* *}$ & $-35.27^{* *}$ & $-66.77^{* *}$ & $-10.84^{* *}$ & $-3.78^{*}$ & $-55.72^{* *}$ \\
\hline Very severe disability & $-19.33^{* *}$ & $-65.10^{*}$ & $-93.28^{* *}$ & $-22.15^{* *}$ & $-46.21^{* *}$ & $-84.75^{* *}$ \\
\hline Deserving indicator & $-46.14^{* *}$ & $-80.22^{* *}$ & $-95.57^{* *}$ & $-59.56^{* *}$ & $-87.43^{* *}$ & $-92.65^{* *}$ \\
\hline Technical aid & $-1.67^{* *}$ & $-9.80^{* *}$ & & $-10.75^{* *}$ & $-21.86^{* *}$ & $-54.90^{* *}$ \\
\hline Caretaker & $-9.24^{* *}$ & $-59.72^{* *}$ & & $-38.98^{* *}$ & $-45.64^{* *}$ & \\
\hline Disability for: & & & & & & \\
\hline Seeing & $-15.60^{* *}$ & $-22.25^{* *}$ & $-49.61^{* *}$ & $-62.23^{* *}$ & & $-70.12^{* *}$ \\
\hline Hearing & $-7.55^{* *}$ & $-40.33^{* *}$ & & $-60.29^{* *}$ & & \\
\hline Communicating & $-9.62^{* *}$ & $-30.32^{* *}$ & & $-55.17^{* *}$ & & \\
\hline Remembering & $-3.79^{* *}$ & $-17.23^{* *}$ & & & & \\
\hline Executing orders & $-24.14^{* *}$ & $-20.05^{* *}$ & & & & \\
\hline Maintaining body postures & $-2.77^{* *}$ & $30.41^{* *}$ & $22.06^{*}$ & $27.93^{* *}$ & $-0.84^{* *}$ & $-73.54^{* *}$ \\
\hline Using hands and fingers & $-3.11^{* *}$ & $58.77^{* *}$ & & $30.16^{* *}$ & $-15.22^{* *}$ & $88.77^{* *}$ \\
\hline Moving outside home & $-27.53^{* *}$ & $62.33^{* *}$ & & $15.08^{* *}$ & $-90.66^{* *}$ & $79.84^{* *}$ \\
\hline Taking care of oneself & $-18.32^{* *}$ & $-38.97^{* *}$ & $-32.55^{* *}$ & $-38.60^{*}$ & $-62.87^{* *}$ & \\
\hline Doing housework & $-16.59^{* *}$ & $31.79^{* *}$ & & $23.49^{* *}$ & $-52.20^{* *}$ & $90.28^{* *}$ \\
\hline Relating & $-16.42^{* *}$ & $-32.70^{* *}$ & & $-26.34^{*}$ & $-42.94^{* *}$ & $-54.94^{* *}$ \\
\hline Log likelihood & -1129.1091 & -210.1244 & -10.6383 & -28.90736 & -79.5386 & -36.8550 \\
\hline$R^{2}(1)$ & 0.7945 & 0.5891 & 0.6891 & 0.7685 & 0.5539 & 0.6723 \\
\hline Gamma-Kruskal(2) & 0.8146 & 0.6994 & 0.8472 & 0.6764 & 0.8780 & 0.7651 \\
\hline & $(0.019)$ & $(0.181)$ & $(0.014)$ & $(0.163)$ & $(0.088)$ & $(0.163)$ \\
\hline
\end{tabular}

** and ${ }^{*}$ denote significance at the 1 and $5 \%$, respectively.

Baseline: male, single, high school education, skilled occupation, aged 50-54, moderate disability.

(1): $R^{2}$ McKelvey and Zavoina adjusted r-squared

(2): Goodman-Kruskal's Gamma statistics, asymptotic standard error within brackets

Table B.5. Probability of working at $t_{2}$ and marginal effects (sample 4).

\begin{tabular}{|l|r|r|r|l|c|c|c|}
\cline { 2 - 5 } \multicolumn{1}{c|}{} & $\mathrm{P}\left[\mathrm{W}_{2}\right.$ & \multicolumn{1}{|c|}{ M.E. } & $\mathrm{t}$ & & $\mathrm{P}\left[\mathrm{W}_{2}\right.$ & $\mathrm{M} . \mathrm{E}$ & $\mathrm{t}$ \\
\hline Baseline & 0.810 & - & - & & & \\
Woman & 0.726 & -0.106 & -3.47 & Very severe disability & & -0.285 & -4.12 \\
Married & 0.924 & 0.140 & 3.45 & Deserving indicator & 0.539 & -0.335 & -3.98 \\
Spouse working & 0.912 & 0.126 & 2.67 & Technical aid & 0.764 & -0.056 & -2.93 \\
Spouse retired/DB & 0.620 & -0.235 & -3.45 & Caretaker & 0.588 & -0.274 & -3.12 \\
Main breadwinner & 0.970 & 0.198 & 2.57 & Disability for: & & & \\
Impairment certificate & 0.640 & -0.210 & -2.40 & Seeing & 0.621 & -0.234 & -4.05 \\
Change of house & 0.741 & -0.086 & -4.51 & Hearing & 0.689 & -0.149 & -3.58 \\
Rehabilitation treatment & 0.712 & -0.121 & -7.25 & Communicating & 0.578 & -0.286 & -3.73 \\
No elementary & 0.685 & -0.155 & -2.84 & Remembering & 0.538 & -0.336 & -3.90 \\
Elementary & 0.784 & -0.032 & -3.81 & Executing orders & 0.608 & -0.249 & -4.91 \\
College & 0.824 & 0.0171 & 3.22 & Maintaining body postures & 0.672 & -0.170 & -4.70 \\
Unskilled & 0.564 & -0.306 & -3.12 & Using hands and fingers & 0.651 & -0.196 & -4.85 \\
White collar & 0.947 & 0.169 & 4.04 & Moving outside home & 0.659 & -0.187 & -4.86 \\
Age (55,60] & 0.733 & -0.095 & -2.89 & Taking care of oneself & 0.579 & -0.285 & -4.77 \\
Age (60,65] & 0.647 & -0.202 & -2.71 & Doing housework & 0.638 & -0.212 & -4.89 \\
Severe disability & 0.692 & -0.146 & -3.15 & Relating & 0.667 & -0.177 & -4.92 \\
\hline
\end{tabular}

Baseline: male, single, high school education, skilled occupation, aged 50-54, moderate disability. 
Figure 1. Prob. of keeping work at $t_{1}$

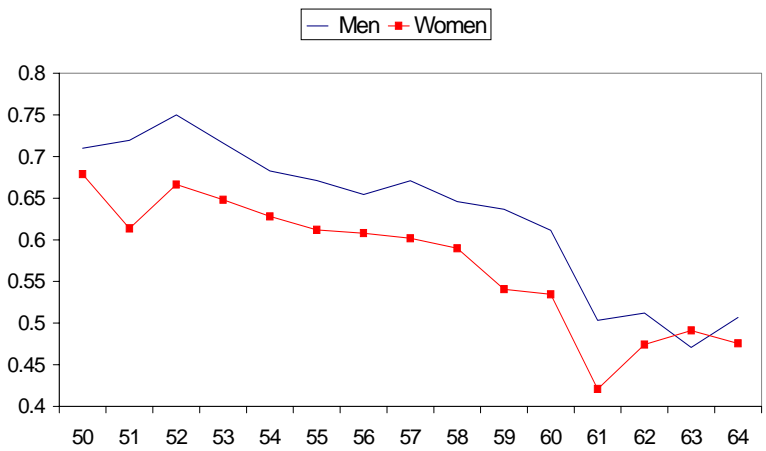

Figure 3. $\operatorname{Prob}\left(U_{2} \mid U_{1}\right)$ by age and severity

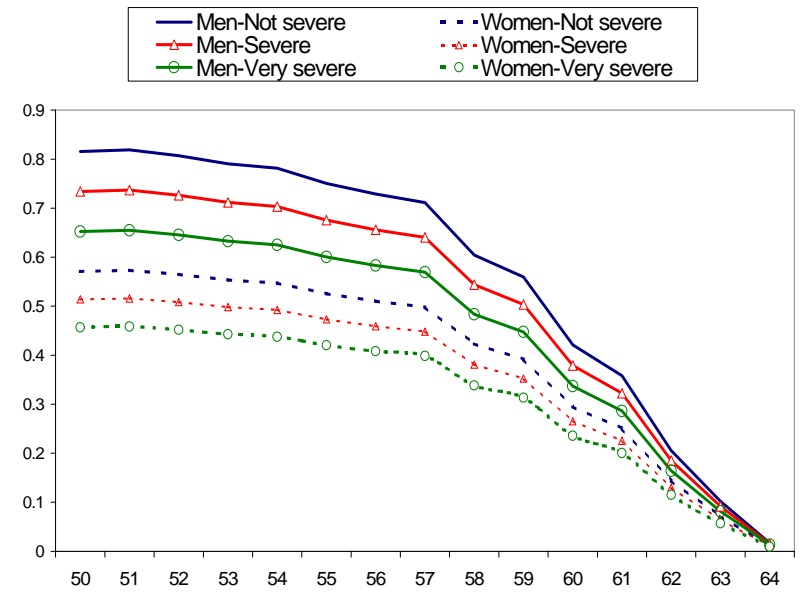

Figure $5 . \operatorname{Prob}\left(W_{2} \mid U_{1}\right)$ by age and severity

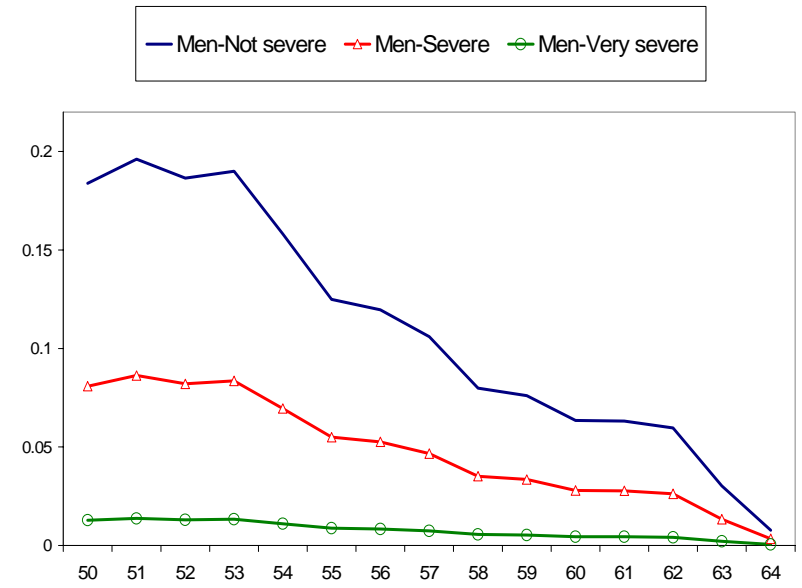

Figure 2. $\operatorname{Prob}\left(U_{1} \mid N W_{1}\right)$

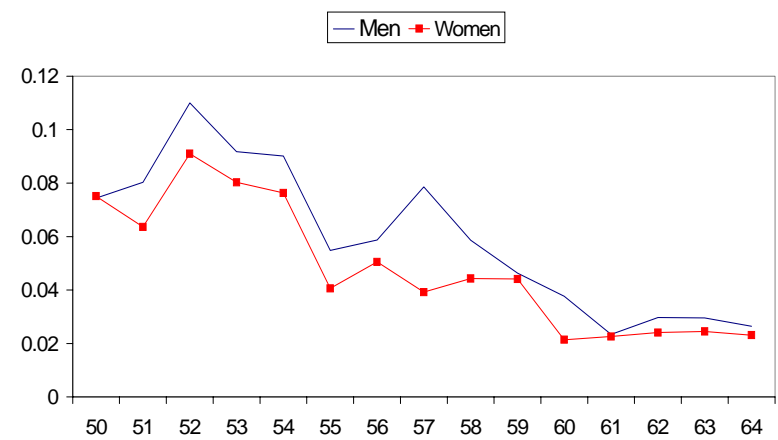

Figure 4. $\operatorname{Prob}\left(U_{2} \mid U_{1}\right)$ by years since shock

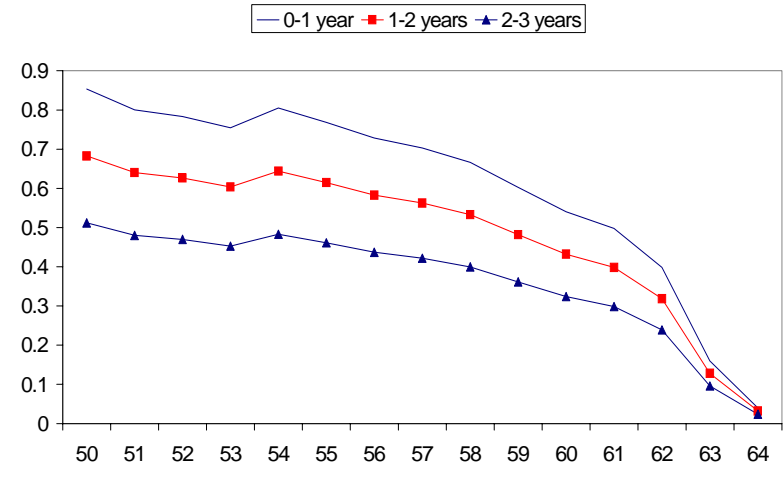

Figure $6 . \operatorname{Prob}\left(W_{2} \mid U_{1}\right)$ by years since shock

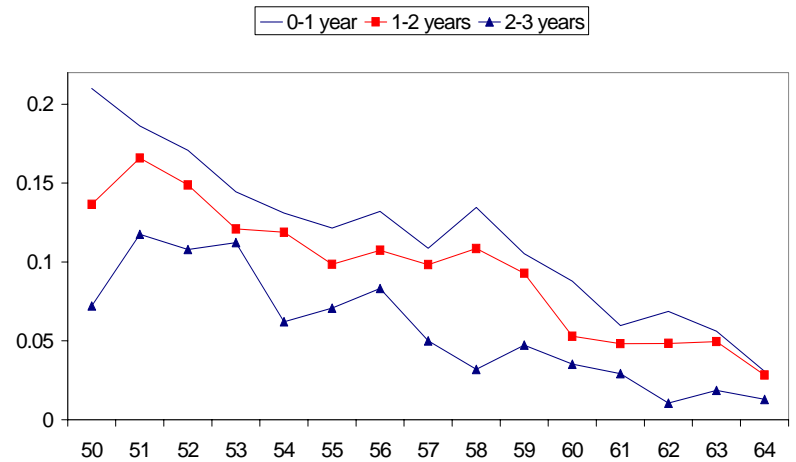


Figure $7 . \operatorname{Prob}\left(W_{2} \mid I_{1}\right)$ by age and severity

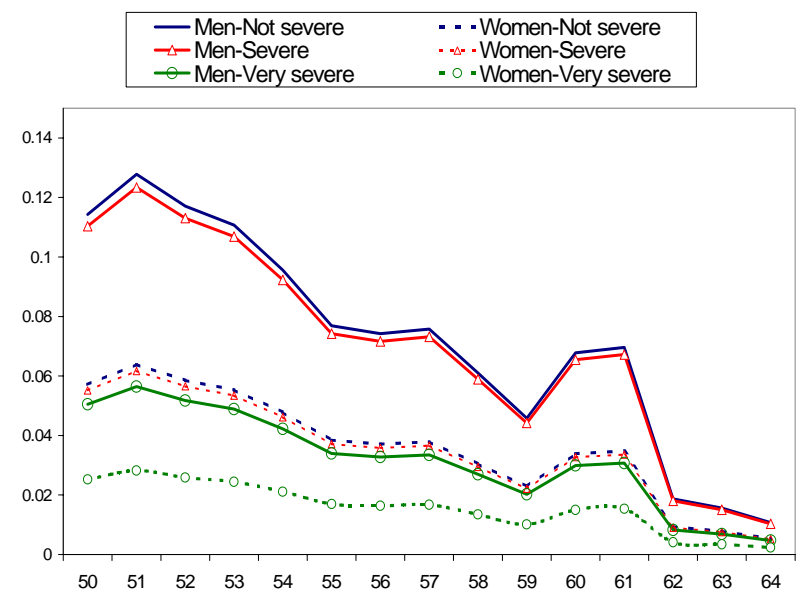

Figure $8 . \operatorname{Prob}\left(W_{2} \mid I_{1}\right)$ by years since shock

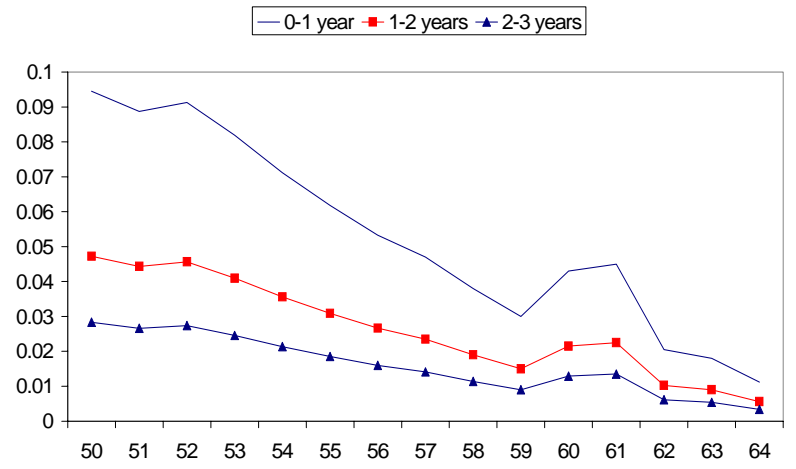

Figure 9. Total $\operatorname{Prob}\left(W_{2}\right)$ by age and professional status

\section{$\square 50-54 \square 55-59 \square 60-64$}

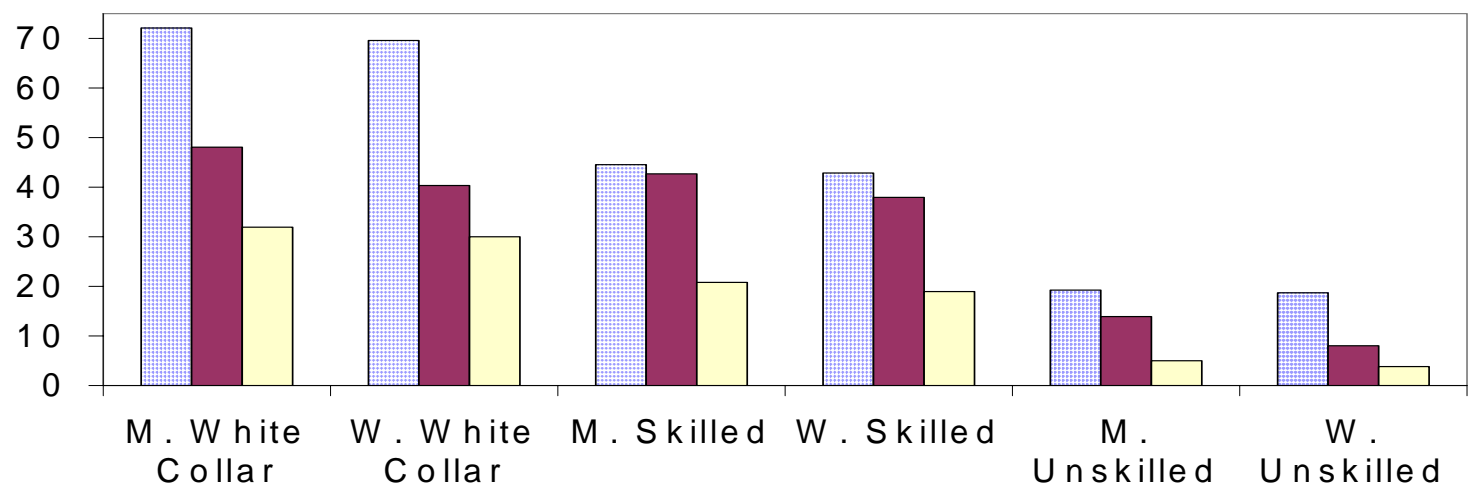


Figure 10. Density functions for standard errors and loss function for the estimated models
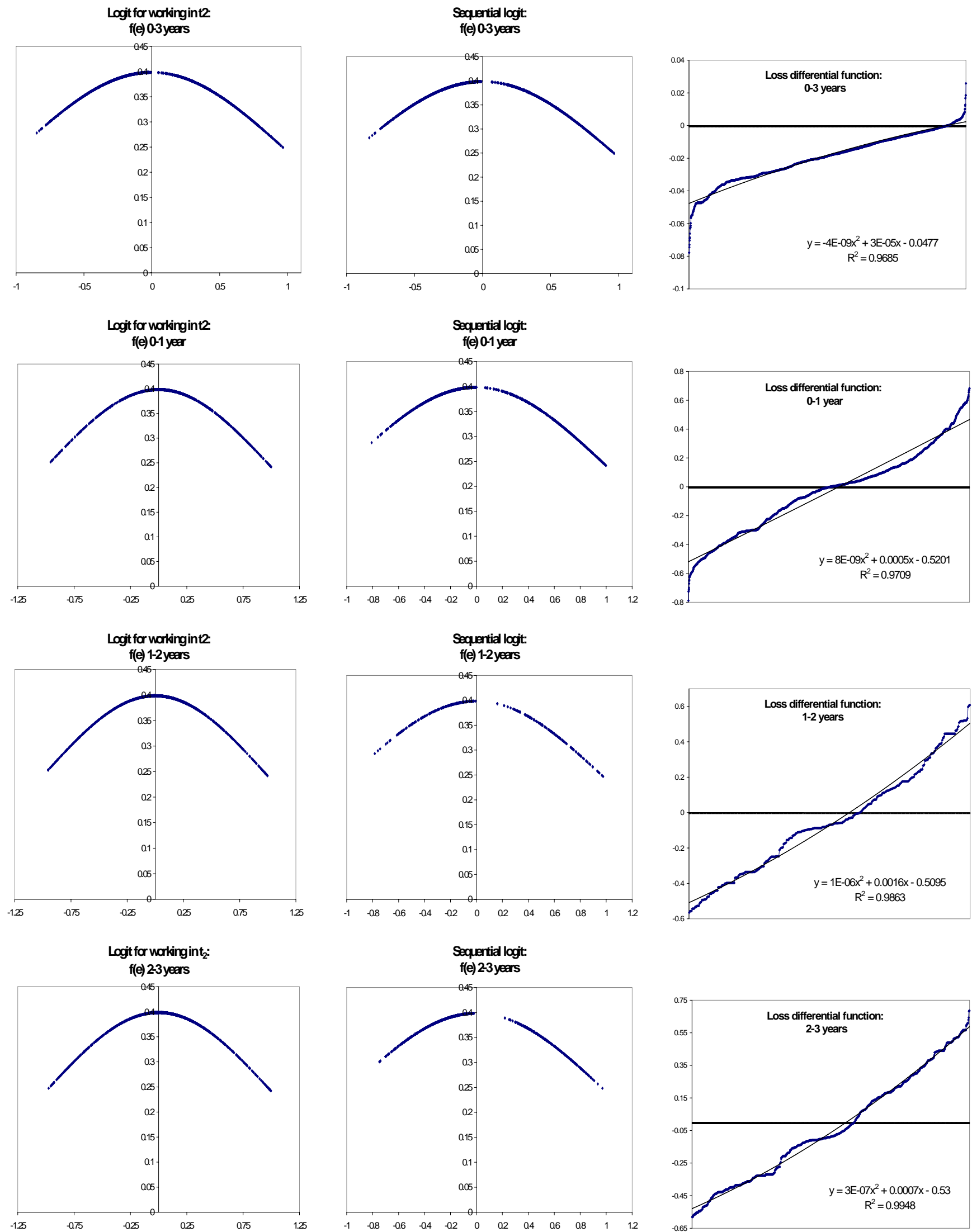